\title{
Bridging Adsorption Analytics and Catalytic Kinetics for Metal-Exchanged Zeolites
}

\section{Pengfei Xie}

Johns Hopkins University https://orcid.org/0000-0002-7644-9934

\section{Tiancheng Pu}

Johns Hopkins University

\section{Gregory Aranovich}

Johns Hopkins University

Jiawei Guo

University of California, Davis

Marc Donohue

Johns Hopkins University

Ambarish Kulkarni

University of California, Davis

Chao Wang ( $\sim$ chaowang@jhu.edu )

Johns Hopkins University https://orcid.org/0000-0001-7398-2090

\section{Article}

Keywords: adsorption compression, NO decomposition, copper-exchanged zeolites, kinetics

Posted Date: September 3rd, 2020

DOI: https://doi.org/10.21203/rs.3.rs-63384/v1

License: (c) (1) This work is licensed under a Creative Commons Attribution 4.0 International License.

Read Full License

Version of Record: A version of this preprint was published at Nature Catalysis on February 1st, 2021. See the published version at https://doi.org/10.1038/s41929-020-00555-0. 


\section{Bridging Adsorption Analytics and Catalytic Kinetics for Metal-Exchanged Zeolites}

Pengfei Xie, ${ }^{1}$ Tiancheng Pu, ${ }^{l}$ Gregory Aranovich, ${ }^{1}$ Jiawei Guo, ${ }^{2}$ Marc Donohue, ${ }^{l}$ Ambarish Kulkarni, ${ }^{2}$ * Chao Wang $^{l, *}$

${ }^{1}$ Department of Chemical and Biomolecular Engineering, Johns Hopkins University, Baltimore, Maryland 21218, United States

${ }^{2}$ Department of Chemical Engineering, University of California, Davis, California 95616, United States

KEYWORDS: adsorption compression, NO decomposition, copper-exchanged zeolites, kinetics 


\begin{abstract}
.
Metal-exchanged zeolites have been widely used in industrial catalysis and separation, but fundamental understanding of their structure-property relationships has remained challenging, largely due to the lack of quantitative information concerning the atomic structures and reactionrelevant adsorption properties of the embedded metal active sites. We report on the use of lowtemperature chemisorption to titrate $\mathrm{Cu}$-exchanged ZSM5. Quantitative descriptors of the atomic structures and adsorption properties of $\mathrm{Cu}$-ZSM5 are established by combining atomistic simulation, DFT calculations, operando molecular spectroscopy, chemisorption and titration measurements. These descriptors are then applied to interpret the catalytic performance of $\mathrm{Cu}-$ ZSM5 for NO decomposition. Linear correlations are established to bridge the low-temperature adsorption analytics and high-temperature reaction kinetics, which are demonstrated to be generally applicable for understanding the structure-property relationships of metal exchanged zeolites and foregrounded for guiding the development of advanced catalytic materials.
\end{abstract}




\section{INTRODUCTION}

Portraiture of active sites and their adsorption properties represents a grand challenge but utmost task for the development of advanced catalysts. Conventionally it largely relies on microscopic and spectroscopic techniques to characterize the structures of catalytic materials and probe reaction-relevant adsorbates, respectively. ${ }^{1,2}$ These approaches are, however, either limited by the insensitivity to the active sites on catalyst surfaces (e.g., for transmission electron microscopy, $\mathrm{TEM}^{2}$ and X-ray absorption spectroscopy, $\mathrm{XAS}^{3}$ ), or subject to the rendered signal-to-noise ratios at elevated reaction temperatures and inadequacy of acquiring quantitative information (such as infrared ${ }^{4}$ and $\operatorname{Raman}^{5}$ spectroscopy). On the other hand, computational approaches such as density functional theory (DFT) calculations are extensively used to simulate reaction pathways and understand catalytic mechanisms, with energetics of adsorbing intermediates commonly established as descriptors to understand the trends of kinetic performance and guide catalyst designs. ${ }^{6,7}$ But such calculations usually require pre-established structure models of catalytic materials and quantitative validation of the computed structure-property relationships are nontrivial in experiments.

Direct decomposition of $\mathrm{NO}$ to $\mathrm{N}_{2}$ and $\mathrm{O}_{2}$ is the most robust strategy for $\mathrm{NO}$ removal from combustion emissions, as it does not rely on the presence or addition of reductants to the exhaust stream. ${ }^{8,9} \mathrm{Cu}$-ZSM5 represents a promising and extensively studied catalyst for this reaction. Both isolated monomeric ${ }^{10-13}$ and associated dimeric ${ }^{14-17} \mathrm{Cu}$ sites have been discussed as the active sites. The $\mathrm{Cu}$ dimers in $\mathrm{Cu}-\mathrm{ZSM} 5$ have been probed by using various spectroscopic techniques, including ultraviolet-visible spectroscopy (UV-Vis), ${ }^{18-20}$ Fourier-transform infrared spectroscopy (FTIR), ${ }^{20-25}$ resonance Raman spectroscopy (Raman), ${ }^{26,27}$ electron paramagnetic resonance $(\mathrm{EPR})^{28-30}$ and $\mathrm{XAS}^{21,31-33}$. Computational studies also support the formation of dicopper-oxo 
centers $\left([\mathrm{Cu}-\mathrm{O}-\mathrm{Cu}]^{2+}\right)$ when $\mathrm{NO}_{x}\left(\mathrm{NO}^{34,35}\right.$ or $\left.\mathrm{N}_{2} \mathrm{O}^{36}\right)$ interacts with $\mathrm{Cu}-\mathrm{ZSM} 5$. Albeit the abundant evidence for their formation and involvement in the NO decomposition reaction, quantitative characterization of the $\mathrm{Cu}$-dimer motifs remains largely challenging. The overall low population and small coordination number (up to $\mathrm{CN}=1$ for $\mathrm{Cu} \cdots \mathrm{Cu}$ coordination if all the $\mathrm{Cu}$ sites are in dimeric configurations such as $[\mathrm{Cu}-\mathrm{O}-\mathrm{Cu}]^{2+}$ ) of $\mathrm{Cu}$ sites cause large uncertainties in the assignment of the second-shell feature in EXAFS spectra. ${ }^{31,32}$ Temperature-programmed reaction (TPR) measurements have been reported to quantify $\mathrm{Cu}$ dimers in oxygen-pretreated $\mathrm{Cu}$-ZSM5 of a fixed $\mathrm{Si} / \mathrm{Al}$ ratio with different $\mathrm{Cu}$ exchange levels, but it remains elusive whether this means is generally applicable. ${ }^{37}$ Such measurements are also limited due to the inability of obtaining reaction-relevant structure information and adsorption properties, due to the different chemical conditions (e.g., $\mathrm{O}_{2}$ vs. $\mathrm{NO}_{x}$ ) involved in TPR as compared to the catalytic process. Similar challenges are also present for other metal-exchanged zeolites that are of broad interests in catalysis and separation. ${ }^{38-42}$

We report here the use of reactive adsorption to titrate the atomic structures and adsorption properties of metal-exchanged zeolites. On the basis of a series of Cu-exchanged ZSM5 with different $\mathrm{Si} / \mathrm{Al}$ ratios but all at full exchange, we first performed atomistic simulations to quantify the $\mathrm{Cu}$ dimers within the pentasil framework, and conducted temperature-programmed reaction (TPR) measurements to validate the predicted descriptor. We then combined DFT calculations, diffuse reflectance infrared Fourier transform spectroscopy (DRIFTS) and chromatographic titration of gaseous effluents to evaluate the low-temperature interaction of $\mathrm{NO}$ with the series of Cu-ZSM5. Reaction-relevant adsorption analytics were derived to establish correlations between the atomic structures and adsorption properties of the $\mathrm{Cu}$ sites, which were then employed to interpret the kinetics of NO decomposition catalyzed by Cu-ZSM5. We further generalized these relationships to understand the structure-performance correlations for other types of zeolites in NO 
decomposition and also for Cu-ZSM5 in catalyzing methane-to-methanol (MTM) conversion. Our work aims to excel the bridge between low-temperature adsorption analytics and high-temperature reaction kinetics in heterogeneous catalysis.

\section{RESULTS AND DISCUSSION}

Synthesis of Cu-ZSM5. We first prepared a series of pristine ZSM5 with different Si/Al ratios $(11.5,20,30,50$ and 100, as determined by X-ray fluorescence (XRF) spectroscopy) by using hydrothermal synthesis. ${ }^{43,44}$ The as-synthesized ZSM5 exhibits a rectangular parallelepiped shape with the over particle size in the micrometer scale (Figure S1). They were converted into Na-type and then $\mathrm{Na}^{+}$was substituted with $\mathrm{Cu}^{2+}$ via ion exchange (see the Experimental Method). ${ }^{45,46} \mathrm{~A}$ $\mathrm{Cu} / \mathrm{Al}$ ratio of $\sim 0.5$ was targeted for full exchange (Table 1$).{ }^{46} \mathrm{In}$ the following discussion, the $\mathrm{Cu}$ exchanged zeolites are denoted as Cu-ZSM5-x, where $x$ represents the $\mathrm{Si} / \mathrm{Al}$ element ratio, e.g., Cu-ZSM5-11.5 for Cu-ZSM5 with Si/Al 11.5. Brunauer-Emmett-Teller (BET) measurements show that the five types of $\mathrm{Cu}$-ZSM5 have rather consistent specific surface areas in the range of $370-400 \mathrm{~m}^{2} \mathrm{~g}^{-1}$ (Table 1, also see Figure $\mathrm{S} 2$ for the $\mathrm{N}_{2}$ adsorption and desorption isotherms). ${ }^{44,47}$ X-ray diffraction (XRD) patterns collected on the Cu-ZSM5 catalysts exhibit peaks corresponding to the MFI phase (JCDPS No. 37-0359) but not for copper oxides $\left(\mathrm{Cu}_{2} \mathrm{O}\right.$ or $\left.\mathrm{CuO}\right)$, indicating that the $\mathrm{Cu}$ species are highly dispersed in the zeolites (Figure S3).

For studying the interaction with NO, the Cu-ZSM5 catalysts were pretreated in $\mathrm{He}$ at 500 ${ }^{\circ} \mathrm{C}$. Post the activation the $\mathrm{Cu}$ species in $\mathrm{Cu}-\mathrm{ZSM} 5$ can be present either as monomers $\left(\left[\mathrm{Cu}^{+}\right]\right)$or in a dimeric configuration $\left[\mathrm{Cu}^{+} \ldots \mathrm{Cu}^{+}\right]$via a so-called "auto-reduction" process, ${ }^{22,31,32,35,48}$ with the charges balanced by one or two proximal Al centers in the framework, respectively (Figures 1a and $1 \mathrm{~b}) .{ }^{48-50}$ This was confirmed by using DRIFTS analysis to track the hydroxyl (O-H) and 
framework features during the pretreatment in $\mathrm{He}$ (Figure S4). For the $\mathrm{Cu}$ dimers, it has been suggested that they are accommodated within the 10-membered ring of ZSM5 and associated with two Al sites separated by one (1T) or two $(2 \mathrm{~T})-\mathrm{SiO}_{4}$ - tetrahedra units by following the Löwenstein's rule. ${ }^{40,57,60} \mathrm{Cu}$ density in the five types of $\mathrm{Cu}$-ZSM5 varies with the $\mathrm{Si} / \mathrm{Al}$ ratio, decreasing from $0.52 \times 10^{-3} \AA^{-3}$ for Cu-ZSM5-11.5 to $0.08 \times 10^{-3} \AA^{-3}$ for Cu-ZSM5-100 (Table 1 and Figure 1c). These values correspond to a nearly linear increase of the average distance between neighboring $\mathrm{Cu}$ sites from 15.4 to $28.8 \AA$. Note that " $\mathrm{Cu}$ density" here refers to the average number of copper sites per unit volume of the zeolite pore, with the latter determined by BET measurements (Table 1 and Figure S2). "Average $\mathrm{Cu} \cdots \mathrm{Cu}$ distance" is determined from the " $\mathrm{Cu}$ density" by assuming a cubic occupation of the $\mathrm{Cu}$ atoms within the unit pore volume, which is different from the actual distance between neighboring $\mathrm{Cu}$ sites to be discussed below. ${ }^{51}$ Previously Schoonheydt and Solomon et al. ${ }^{26,32,36}$ have used XAS, UV-vis, Raman and DFT to determine the geometry of dimeric $\mathrm{Cu}$ motifs in Cu-ZSM5, showing $\mathrm{Cu} \cdots \mathrm{Cu}$ distances of 2.5-4.2 $\AA$ and $\angle \mathrm{Cu}-\mathrm{O}-\mathrm{Cu} \approx 140^{\circ}$. Nonetheless, it remains challenging to quantify the atomic fractions of $\mathrm{Cu}$ dimers $\left(\eta_{\mathrm{Cu} \cdot \cdots \mathrm{Cu}}\right.$, namely the percentage of $\mathrm{Cu}$ atoms being in dimeric configuration) within $\mathrm{Cu}-$ ZSM5 and characterize reaction-relevant adsorbing intermediates by using these methods.

The five types of Cu-ZSM5 form a platform with consistent framework but varying atomic structures of $\mathrm{Cu}$ sites. Upon the interaction with $\mathrm{NO}, \mathrm{Cu}^{+}$can be oxidized to $\mathrm{Cu}^{2+}$, which is associated with structural transformation of the $\mathrm{Cu}$ sites, e.g., formation of oxo-copper centers, and adsorbing nitrogen oxide species. Analysis of these adsorbates thus provides a viable approach toward quantitative titration of $\eta_{\mathrm{Cu} \cdots \mathrm{Cu}}$ and adsorption properties for the metal-exchanged zeolite catalysts. 
Fractions of Cu Dimers within Cu-ZSM5. To quantify the fraction of dimer species within the $\mathrm{Cu}-\mathrm{ZSM} 5$ of various $\mathrm{Si} / \mathrm{Al}$ ratios, we first performed high-throughput periodic $\mathrm{DFT}$ calculations (PBE functional, Grimme D3(BJ) vdW corrections, $500 \mathrm{eV}$ plane wave cutoff, $\Gamma-$ point only, implemented in Vienna ab-initio Simulation Package (VASP)) to calculate the formation energy of all unique $[\mathrm{Cu}-\mathrm{O}-\mathrm{Cu}]^{2+}$ dimer configurations for the MFI topology. Specifically, for each inequivalent $\mathrm{T}$ site position for Al (12 total unique T sites for MFI, Table S1 and S2), we systematically replaced every $\mathrm{T}$ atom by $\mathrm{Al}$ within a threshold distance of $9.0 \AA$, resulting in a database of 167 structures $(\mathrm{Si} / \mathrm{Al}=47,115$ unique configurations). For each of these structures, we calculated dimer formation energies using

$$
\mathrm{Z} C \mathrm{Cu}+\mathrm{Z}^{\prime \prime C u}+0.5 \mathrm{O}_{2} \rightarrow \mathrm{Z}[\mathrm{Cu}-\mathrm{O}-\mathrm{Cu}] \mathrm{Z}^{\prime}+\mathrm{Z}_{\mathrm{Si}}
$$

where, $Z$ ' and $Z$ “ represent one $A 1$ substitution in the MFI framework and $Z_{\mathrm{Si}}$ represents the energy of an all-silica MFI framework. Although direct comparison of various $\mathrm{Z}[\mathrm{Cu}-\mathrm{O}-\mathrm{Cu}] \mathrm{Z}^{\prime \prime}$ configurations is possible (Figure S5), equation (1) allows for separate analysis of the stability of $[\mathrm{CuOCu}]^{2+}$ motifs (which depends on reaction conditions and the oxygen chemical potential) and the underlying Al-distribution (which likely depends on the synthesis conditions). The choice of $\mathrm{O}_{2}$ gas phase reference is motivated by the previous work. ${ }^{52-57}$ Figure $2 \mathrm{a}$ summarizes the distribution of calculated dimer formation energies, with the wide span $(>2.5 \mathrm{eV})$ likely due to the favorable formation of dimers from certain Al-site pairs. Moreover, Figure $2 \mathrm{~b}$ shows that, although dimers accommodated by the Al pairs separated with one (orange) silicon atom are on average more favorable (dotted lines, Figure 2b), certain configurations (see insets in Figure 2b) separated with two (green) or three Si atoms (red) are also very stable. The formation energies are summarized in Tables S1 and S2 and the optimized periodic structures are provided as an Atomic Simulation Environment database file $\mathrm{e}^{58}$ (ase $\mathrm{db}$ ) in the Supplementary Information. 
As the fraction of dimers formed for a given $\mathrm{Si} / \mathrm{Al}$ ratio will depend on the proximity and distribution of $\mathrm{Al}$ atoms, we used Monte Carlo simulations to create ensembles of structures corresponding to various $\mathrm{Si} / \mathrm{Al}$ ratios to obtain a statistical sampling of the relative $\mathrm{Al}$ locations. As the Al-siting in MFI depends on the synthesis conditions and is still widely debated, ${ }^{59-61}$ we chose to determine the Al distribution using DFT. Specifically, we consider two extremes in Figure 2c: i) the $\mathrm{Al}$ distribution is completely determined by DFT calculated thermodynamics of $\mathrm{Al}$ substitution (i.e., Boltzmann-weighted) and ii) thermodynamics are not relevant and $\mathrm{Al}$ distributes randomly. In conjunction with the dimer formation energies in Figure $2 \mathrm{~b}$ and after incorporation of entropic effects, these ensembles of $\mathrm{Al}$ distributions are used to estimate $\eta_{\mathrm{Cu} \cdots \mathrm{Cu}}$ for each $\mathrm{Si} / \mathrm{Al}$ ratio at $80{ }^{\circ} \mathrm{C}$ (the temperature used in our titration experiments; see the Experimental Method). Realizing that some $\mathrm{Al}$ atoms are capable of stabilizing $[\mathrm{CuOCu}]^{2+}$ dimers with multiple other $\mathrm{Al}$ atoms (especially at low $\mathrm{Si} / \mathrm{Al}$ ratios), we populate the $\mathrm{Al}$ sites by starting with the most favorable $[\mathrm{CuOCu}]^{2+}$ dimer configurations. Once an $\mathrm{Al}$ pair is assigned with a $\mathrm{Cu}$ dimer, the two $\mathrm{Al}$ atoms are excluded from further assignment of less stable dimers. Using this approach, the value of $\eta_{\mathrm{Cu}}$. ..Cu predicted according to the Boltzmann-weighted distribution (case $i$ )) varies from 0.79 for $\mathrm{Cu}$ ZSM5-11.5 to 0.20 for Cu-ZSM5-100. In general, the Boltzmann-weighted distribution of Al atoms gives an approximately $20-30 \%$ higher $\eta_{\mathrm{Cu} \cdots \mathrm{Cu}}$ than the random $\mathrm{Al}$ distribution (case $\left.i i\right)$ ). More broadly, the calculated $\eta_{\mathrm{Cu} \cdots \mathrm{Cu}}$ based on both Boltzmann and random distributions exhibits nearly linear dependence on the average $\mathrm{Cu}$ site density (Figure 2d). This correlation confirms that our simulation captures the higher tendency of forming $\mathrm{Cu}$ dimers for lower $\mathrm{Si} / \mathrm{Al}$ ratios due to the closer proximity of $\mathrm{Al}$ atoms. As also shown in Figures $2 \mathrm{c}$ and $\mathrm{d}, \eta_{\mathrm{Cu}} \ldots \mathrm{Cu}$ has a non-liner dependence on the $\mathrm{Si} / \mathrm{Al}$ ratio. Results for other temperatures (Figure $\mathrm{S} 6$ ) indicate that, although the fraction of dimers reduces slightly at higher temperatures, the overall trends remain the same 
as the $[\mathrm{CuOCu}]^{2+}$ dimer can be stabilized by multiple types of Al pairs. This suggests that the MFI topology is favorable for formation of dimers, and as we will show later, low-temperature adsorption measurements can be used to probe the active sites relevant to high-temperature reactivities.

Although Cu-ZSM5 has been extensively studied, only a few reports are present for experimental quantification of the $\mathrm{Cu}$ dimer fractions. Iglesia et al. ${ }^{37}$ used $\mathrm{CO} / \mathrm{H}_{2}-\mathrm{TPR}$ to evaluate

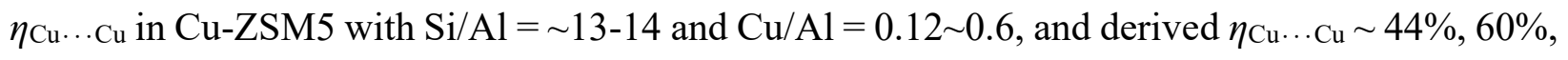
and $70 \%$ for $\mathrm{Cu}$-ZSM5 with $\mathrm{Cu} / \mathrm{Al}=0.12,0.38,0.58$ respectively. Owing to the limited follow-up studies using this method, its general applicability is still to be demonstrated. Moreover, $\mathrm{CO} / \mathrm{H}_{2-}$ TPR cannot provide information about the atomic structures and adsorption properties that are pertinent to the catalytic applications (e.g., in the presence of $* \mathrm{NO}_{x}$ for $\mathrm{NO}$ decomposition and SCR). Moretti et al. ${ }^{35}$ combined irreversible $\mathrm{CO}$ adsorption at $298 \mathrm{~K}$ and $\mathrm{N}_{2}$ adsorption at $273 \mathrm{~K}$ to evaluate the abundance of $\mathrm{Cu}$ dimers in $\mathrm{Cu}-\mathrm{ZSM} 5$ by assuming strong and selective adsorption of $\mathrm{N}_{2}$ on $\mathrm{Cu}$ dimers. But this method was later on questioned by Itadani et al. ${ }^{62}$, who studied $\mathrm{N}_{2}$ adsorption on Cu-MFI using a series of spectroscopic methods, including photoluminescence, $\mathrm{X}$ ray absorption and infrared, and concluded with selective adsorption of $\mathrm{N}_{2}$ on monomeric $\mathrm{Cu}^{+}$, rather than $\mathrm{Cu}$ dimers. Henriques et al. ${ }^{63}$ attempted to use EPR measurements to obtain quasiquantitative information of the atomic structures of $\mathrm{Cu}$ sites within $\mathrm{Cu}$-ZSM5, but debates are present on the corresponding peak assignments. ${ }^{28} \mathrm{We}$ have performed $\mathrm{CO} / \mathrm{H}_{2}-\mathrm{TPR}$ measurements on the series of Cu-ZSM5- $x$ with pretreatment in oxygen (i.e., $500{ }^{\circ} \mathrm{C}$ for ca. $2 \mathrm{~h}$, to induce the formation of $[\mathrm{Cu}-\mathrm{O}-\mathrm{Cu}]^{2+}$ centers) (Figure S7 and Table S3). Figure $2 \mathrm{~d}$ summarizes the data collected from both the literature ${ }^{37}$ and our own $\mathrm{CO} / \mathrm{H}_{2}-\mathrm{TPR}$ measurements with similar pretreatments. The results largely resemble the linear relationship correlating the $\eta_{\mathrm{Cu}} \ldots \mathrm{Cu}$ 
calculated based on the Boltzmann distribution and dimer formation via eq. (1) to the average $\mathrm{Cu}$ site density. The fact that our predictions are in close agreement with these experiments does not only validate the predicted distribution and structures of $\mathrm{Cu}$ sites, but also suggests that the established linear scaling relationship is intrinsic to the zeolite supported metal sites. The initial Boltzmann Al distributions are obtained using only the energetics of substituting a single Si atom by a single $\mathrm{Al}$ (with the most favorable Bronsted $\mathrm{H}$ location, Table $\mathrm{S} 1$ ). While the existing $\mathrm{Al}$ atoms may influence the siting of the other Al, such analyses are beyond the scope of this work. While not discussed here, we note that the above Monte Carlo approach can be extended based on the experimentally-determined $\mathrm{Al}$ positions that are influenced by kinetic factors. Moreover, we acknowledge that migration of $\mathrm{Al}$ sites is also possible during the oxidative pretreatment and the process of $\mathrm{Cu}$ dimer formation. ${ }^{53,64}$

Reactive Adsorption of NO on Cu-ZSM5. As noted, the $\eta_{\mathrm{Cu}} \cdots \mathrm{Cu}$ evaluated using $\mathrm{CO} / \mathrm{H}_{2}-$ TPR cannot be directly related to the active sites involved in the NO decomposition reaction. This is due to the dissimilar formation energies of dicopper-oxo centers upon exposure to different oxidants (e.g., $\mathrm{O}_{2}, \mathrm{H}_{2} \mathrm{O}_{2}$ and $\mathrm{N}_{2} \mathrm{O}$ ). ${ }^{19,27,65,66}$ To merge this gap, we turned to evaluate the reactive adsorption of $\mathrm{NO}$ on $\mathrm{Cu}-\mathrm{ZSM} 5$, aiming at probing the structure and property of the $\mathrm{Cu}$ sites under reaction-relevant environments. We also started with calculations of free energies for the various nitrogenous adsorbates and reaction barriers possibly involved in the interaction between NO and the $\mathrm{Cu}$ sites (using nudged-elastic band and dimer method). Consistent with the previously reported approaches, ${ }^{67-70}$ the simulation was primarily applied to $1 \mathrm{~T}$ and $2 \mathrm{~T}$ site models (Figure 3a). A more extensive analysis by applying ensemble average to the comprehensive set of data presented in Figure 2 is currently underway and will be reported in a separate study. NO decomposition on the $\left[\mathrm{Cu}^{+} \cdots \mathrm{Cu}^{+}\right]$dimer sites involves three barriers related to bending of the $\mathrm{NO}$ 
molecule (TS1), cleaving of the first N-O bond to form the $[\mathrm{Cu}-\mathrm{O}-\mathrm{Cu}]^{2+}$ dimer (TS2) and reaction of $\mathrm{N}_{2} \mathrm{O}$ with the $[\mathrm{Cu}-\mathrm{O}-\mathrm{Cu}]^{2+}$ dimer for $\mathrm{O}_{2}$ formation (TS3), where the barrier TS3 $(1.6 \mathrm{eV}$, Figure $3 \mathrm{~b}$ and $3 \mathrm{c}$ ) likely inaccessible at $80^{\circ} \mathrm{C}\left(\right.$ rate $\left.\sim 10^{-10} \mathrm{~s}^{-1}\right)$. Moreover, the single NO bound state NO$[\mathrm{Cu}-\mathrm{O}-\mathrm{Cu}]^{2+}$ (blue, Figure $3 \mathrm{~d}$ ) is predicted to be most favorable at relatively low temperatures (e.g., below $100{ }^{\circ} \mathrm{C}$ ), although binding of $\mathrm{N}_{2} \mathrm{O}$ (black) or a second $\mathrm{NO}$ (orange, Figure 3e) is within 0.2 $\mathrm{eV}$. Finally, the reaction of desorbed $\mathrm{N}_{2} \mathrm{O}$ with a second $\left[\mathrm{Cu}^{+} \cdots \mathrm{Cu}^{+}\right]$site is favorable and results in the formation of $\mathrm{N}_{2}$ (see Figure S8 and Scheme S1 and the Supplementary Information for details of reaction mechanism and calculated atomic structures of the intermediates based on DFT).

To validate the predicted reaction pathway, we have used diffuse reflectance infrared Fourier transform spectroscopy (DRIFTS) to characterize the stable adsorbates formed on $\mathrm{Cu}$ ZSM5 upon interaction with NO. Figure 4a presents the time-dependent spectra collected on $\mathrm{Cu}-$ ZSM5-11.5 under the flow of $1500 \mathrm{ppm} \mathrm{NO}$ at $80^{\circ} \mathrm{C}$ (see the temporal profiles for the other four zeolites in Figure S9). Figures $4 b$ and $4 c$ show comparisons of the spectra recorded on Cu-ZSM511.5 with different partial pressures of $\mathrm{NO}\left(P_{\mathrm{NO}}\right)$ and on different Cu-ZSM5 with $1500 \mathrm{ppm}$ of NO, respectively (all at 15 min, see Figures S10 and S11 for more comprehensive comparisons). The corresponding peak assignments are summarized in Table S4.

The spectra recorded on Cu-ZSM5-11.5 are featured with two peaks located at 1903 and $1813 \mathrm{~cm}^{-1}$. Intensities of these two peaks exhibit an inverse relationship in the dependence of time before saturation was reached at $\sim 15 \min$ (Figures $4 \mathrm{~d}$ and S12). As reported by Beutel et al. ${ }^{22}$ this behavior can be attributed to the oxidation of $\mathrm{Cu}^{+}$and formation of dicopper-oxo centers via the following reactions, rationalized by the measured slope of -1 , assuming that extinction coefficients of $\mathrm{NO}$ on $\mathrm{Cu}^{+}$and $\mathrm{Cu}^{2+}$ are similar :

$$
\left[\mathrm{Cu}^{+} \ldots \mathrm{Cu}^{+}\right]+2 \mathrm{NO} \rightarrow\left[(\mathrm{ON}) \mathrm{Cu}^{+} \cdots \mathrm{Cu}^{+}(\mathrm{NO})\right]
$$




$$
\begin{aligned}
& {\left[(\mathrm{ON}) \mathrm{Cu}^{+} \cdot \mathrm{Cu}^{+}(\mathrm{NO})\right] \rightarrow[\mathrm{Cu}-\mathrm{O}-\mathrm{Cu}]^{2+}+\mathrm{N}_{2} \mathrm{O}} \\
& {[\mathrm{Cu}-\mathrm{O}-\mathrm{Cu}]^{2+}+\mathrm{NO} \rightarrow \mathrm{NO}-[\mathrm{Cu}-\mathrm{O}-\mathrm{Cu}]^{2+}} \\
& \mathrm{NO}-[\mathrm{Cu}-\mathrm{O}-\mathrm{Cu}]^{2+}+\mathrm{NO} \rightarrow[(\mathrm{NO}) \mathrm{Cu}-\mathrm{O}-\mathrm{Cu}(\mathrm{NO})]^{2+}
\end{aligned}
$$

where the transition from the $1813 \mathrm{~cm}^{-1}$ peak to $1903 \mathrm{~cm}^{-1}$ indicates the conversion of $\left[(\mathrm{ON}) \mathrm{Cu}^{+} \cdots \mathrm{Cu}^{+}(\mathrm{NO})\right]$ to one or two $\mathrm{NO}$ molecules bound to $[\mathrm{Cu}-\mathrm{O}-\mathrm{Cu}]^{2+}$. Our assignment is further corroborated by the DRIFTS spectra collected at saturation (15 min) under $p_{\mathrm{NO}}$ (Figure $4 \mathrm{~b}$ ). As $P_{\mathrm{NO}}$ is increased from 300 to $1500 \mathrm{ppm}$, the intensity of the $1813 \mathrm{~cm}^{-1}$ peak diminishes, whereas that for the $1903 \mathrm{~cm}^{-1}$ peak grows (Figure S13). Similar to the temporal response, this transition with $p_{\mathrm{NO}}$ is also associated with the transformation from $\left[(\mathrm{ON}) \mathrm{Cu}^{+} \ldots \mathrm{Cu}^{+}(\mathrm{NO})\right]$ to $\mathrm{NO}-[\mathrm{Cu}-\mathrm{O}-\mathrm{Cu}]^{2+}$ (including both one and two $\mathrm{NO}$ per $\mathrm{Cu}$-dimer site, $[(\mathrm{NO}) \mathrm{Cu}-\mathrm{O}-\mathrm{Cu}]^{2+}$ and $[(\mathrm{NO}) \mathrm{Cu}-\mathrm{O}-\mathrm{Cu}(\mathrm{NO})]^{2+}$, respectively) as a result of the equilibrium shift of reactions (2-5) toward the right-hand sides at increasing concentrations of NO. These assignments are also consistent with DFT-predicted stable adsorbates involved in the low-temperature interactions and trends of vibrational frequencies, e.g., for $1 \mathrm{~T} \mathrm{Cu}$-dimer models, NO-[Cu-O-Cu$]^{2+}\left(1871 \mathrm{~cm}^{-1}\right) \approx[(\mathrm{ON}) \mathrm{Cu}-\mathrm{O}-\mathrm{Cu}(\mathrm{NO})]^{2+}\left(1913 \mathrm{~cm}^{-1}\right)$, and $\left[(\mathrm{ON}) \mathrm{Cu}^{+} \cdots \mathrm{Cu}^{+}(\mathrm{NO})\right]\left(1796 \mathrm{~cm}^{-1}\right)$ (Figure S14). Although different dimer configurations may result in small variations in the predicted vibrational frequencies, performing these calculations for all 115 unique positions in MFI is beyond the scope of this work; no significant changes are expected though.

Besides the two primary peaks, minor features are also present at 2156 and $1653 \mathrm{~cm}^{-1}$, both of which exhibit monotonic increase in intensity with time. The peak at $2156 \mathrm{~cm}^{-1}$ can be assigned to $\mathrm{NO}^{+}$associated with the Brønsted acid sites. ${ }^{25}$ The $1653 \mathrm{~cm}^{-1}$ peak was not commonly observed in the previous spectroscopic studies of nitrogenous adsorbates on $\mathrm{Cu}$-ZSM5. It could be associated with the $v_{\text {as }}\left(\mathrm{NO}_{2}\right)$ stretching vibration in dinitrogen trioxide species $\left(\right.$ e.g., $\mathrm{Cu}^{+}-\mathrm{O}_{2} \mathrm{~N}=\mathrm{NO}$, 
with reported peak positions at $\left.1644-1653 \mathrm{~cm}^{-1}\right),{ }^{71,72}$ which has previously been suggested as a critical intermediate for partial reduction of $\mathrm{NO}$ to $\mathrm{N}_{2} \mathrm{O}$ on $\mathrm{Cu}$ monomers. However, this peak exhibits a clear downshift as the $\mathrm{Si} / \mathrm{Al}$ ratio increases, reaching $1636 \mathrm{~cm}^{-1}$ for $\mathrm{Cu}-\mathrm{ZSM} 5-100$ (Figure $4 \mathrm{c}$ ), where the zeolite likely consists of isolated $\mathrm{Cu}$ cations ( $\sim 80 \%$, Fig. $2 \mathrm{~d})$.

Motivated by this observation, we used DFT calculations to study the reaction mechanism on isolated $\mathrm{Cu}$ cations in ZSM-5. ${ }^{67,68,73}$ As summarized in Figure 3d, we concluded that the reaction mechanism proceeds through three transition states: TS1 (rotation of *NO to form *ON), TS2 (breaking of * ONNO to from bound $* \mathrm{O}$ and $\mathrm{N}_{2} \mathrm{O}$ ) and TS3 (reaction of bidente- $\mathrm{NO}_{2}$ to form $* \mathrm{NO}_{3}$ ). Our results show that adsorbed $* \mathrm{NO}_{3}$ (denoted as $\mathrm{ZCu}-\mathrm{NO}_{3}$ ) represents the most stable state of isolated $\mathrm{Cu}$ monomers at low temperatures as the barriers for reactions with $\mathrm{NO}_{2}$ (to form $\mathrm{NO}, 1.6 \mathrm{eV}$ ) and $\mathrm{N}_{2} \mathrm{O}$ (to form $\mathrm{NO}, 2.4 \mathrm{eV}$ ) are likely insurmountable at $80^{\circ} \mathrm{C}$. To further confirm the presence of $\mathrm{ZCu}-\mathrm{NO}_{3}$ for unpaired $\mathrm{Al}$ sites, we calculate the vibrational frequencies for all 12 unique T-sites using DFT. As summarized in Table S5 and also shown as insert in Figure 3d, the DFT predicted frequencies $\left(1607-1650 \mathrm{~cm}^{-1}\right)$ are in very good agreement with experimental measurements $\left(1636 \mathrm{~cm}^{-1}\right)$. Based on the above experimental observations and computational predictions, the interaction of $\mathrm{Cu}$ monomers with $\mathrm{NO}$ can be summarized as

$$
\mathrm{Cu}^{+}+2 \mathrm{NO}+\mathrm{NO}_{2} \rightarrow \mathrm{Cu}-\mathrm{NO}_{3}+\mathrm{N}_{2} \mathrm{O}
$$

After assigning the spectroscopic features, we can now compare the spectra of the five types of $\mathrm{Cu}-\mathrm{ZSM} 5$ with different $\mathrm{Si} / \mathrm{Al}$ ratios. As also shown in Figure 4c, intensities of all the features reduce as the $\mathrm{Si} / \mathrm{Al}$ ratio increases, as expected with the smaller $\mathrm{Cu}$ (or $\mathrm{Al}$ ) site density in the zeolites. Interestingly the relative intensities of the two peaks at $1903 \mathrm{~cm}^{-1}$ and $1653-1636 \mathrm{~cm}^{-}$ ${ }^{1}$ exhibit opposite trends. Specifically, the peak area ratio $\left(1903 \mathrm{~cm}^{-1}\right.$ versus $\left.1653-1636 \mathrm{~cm}^{-1}\right)$ observed from DRIFTS scales well with $\eta_{\mathrm{Cu} u \cdot \mathrm{Cu}}$ as derived from atomistic simulation and TPR 
measurements, with a slope determined to be 6.66 (Figure 4e). As we discussed above, the two DRIFTS peaks are assigned to adsorbates associated with $\mathrm{Cu}$ dimers and monomers, which is also consistent with the relatively high stabilities of $[(\mathrm{NO}) \mathrm{Cu}-\mathrm{O}-\mathrm{Cu}]^{2+}\left(\right.$ or $\left.[(\mathrm{NO}) \mathrm{Cu}-\mathrm{O}-\mathrm{Cu}(\mathrm{NO})]^{2+}\right)$ and $\left[\mathrm{Cu}-\mathrm{NO}_{3}\right]^{+}$motifs associated with the corresponding $\mathrm{Cu}$ sites as suggested by DFT calculations (Figure 3a and S14). We have further compared the previously reported DRIFTS data ${ }^{23,63,74}$ to our results in Figure 4e. As $\eta_{\mathrm{Cu} \cdots \mathrm{Cu}}$ was not resolved in these prior studies, we have estimated it by using the linear scaling relationship established in Figure $2 \mathrm{~d}$ and the reported $\mathrm{Cu}$-site densities. It can be seen that these data points also follow well the linear trend established for the Cu-ZSM5 catalysts in this work. The linear relationship shown in Figure 4e thus not only conforms the more favorable formation of $\mathrm{Cu}$ dimers at higher $\mathrm{Cu}$ site densities even under the reaction-relevant environment, but also indicates that the quantity $\eta_{\mathrm{Cu} \cdots \mathrm{Cu}}$ evaluated from $\mathrm{CO} / \mathrm{H}_{2}-\mathrm{TPR}$ measurements (with oxygen pretreatment, as shown in Figure 2d) is linearly correlated to the Cu-dimer fractions formed upon exposure to $\mathrm{NO}_{x}$. It thus allows for employment of the established $\eta_{\mathrm{Cu}} \cdots \mathrm{Cu}$ to interpret the structures and properties of Cu-ZSM5 under reaction-relevant conditions. ${ }^{35,75}$

Titration of effluents. In addition to the spectroscopic analyses, we have performed independent measurements of the gaseous effluents during the low-temperature interaction of NO with $\mathrm{Cu}$-ZSM5, to acquire more quantitative information of the adsorption properties. This was done under the same temperature and NO partial pressures, i.e., $80{ }^{\circ} \mathrm{C}$ and $300-1500 \mathrm{ppm}$ of NO, by using a plug flow reactor instead of the in-situ DRIFTS cell (see the Experimental Methods and Figure S15). The outlet gas is typically composed of $\mathrm{N}_{2}$ and $\mathrm{N}_{2} \mathrm{O}$ produced from the redox interactions between $\mathrm{NO}$ and the $\mathrm{Cu}$ sites in the zeolites, as well as residual nitric oxide ( $\left.\mathrm{NO}_{\text {res }}\right)$ left in the gas stream (Figures 5a, 5b and $\mathrm{S} 16)$. The rate of $\mathrm{NO}$ adsorption $\left(\mathrm{NO}_{\mathrm{ad}}\right)$ over the course was determined by calculating the mass balance of nitrogen (see the Supplementary Information 
for the details). Quantitative summaries for the different molecule species are provided in Tables S6-S10. It should be pointed here that the differences in flow pattern, flow rate and catalyst loading between these two sets of experiments are not expected to alter the chemical nature and fractions of adsorbates at equilibrium (reached at the end of the adsorption process and determined by the concentration of $\mathrm{NO}$ and temperature), albeit variations in time scales to reach there.

The effluent profiles are featured with a long transient period before saturation, typically composed of three stages. Using $800 \mathrm{ppm}$ NO on Cu-ZSM5-11.5 as an example, Figure 5a shows that during stage (I) (i.e. $0-384 \mathrm{~min}$ ), only $\mathrm{N}_{2}$ is present in the outlet. The concentration of produced $\mathrm{N}_{2}$ initially rises with time and reaches the maximum of $268 \mathrm{ppm}$, and then drops from the peak value to $73 \mathrm{ppm}$. Correspondingly, the $\mathrm{NO}_{\text {ad }}$ profile presents a fast drop from nearly 800 $\mathrm{ppm}$ at the beginning to a minimum of $264 \mathrm{ppm}$, and then a rise to a peak value of $643 \mathrm{ppm}$. The amounts of $\mathrm{NO}_{\text {res }}$ and $\mathrm{N}_{2} \mathrm{O}$ detected in the outlet are negligible in this stage. Stage (II) starts with a fast drop of $\mathrm{NO}_{a d}$ and rise of $\mathrm{N}_{2} \mathrm{O}$, both of which then reach a plateau at $\sim 260-270$ ppm and $\sim 240 \mathrm{ppm}$, respectively. During this period, $\mathrm{N}_{2}$ gradually phases out and no $\mathrm{NO}_{\text {res }}$ is present in the outlet. The last stage (III) is a transition process toward saturation, with both $\mathrm{N}_{2} \mathrm{O}$ and $\mathrm{NO}_{\mathrm{ad}}$ decreasing to zero and $\mathrm{NO}_{\text {res }}$ restoring to the feeding concentration $(800 \mathrm{ppm})$. Similar behaviors are exhibited in the other adsorption profiles recorded on the different types of zeolites and/or at various concentrations of $\mathrm{NO}$, albeit the variations in lengths and concentrations of nitrogenous species in each stage (Figures $5 \mathrm{~b}$ and Figures S16).

The NO adsorption profiles presented above carry on abundant thermodynamic and kinetic information about the redox chemistry between $\mathrm{NO}$ and the $\mathrm{Cu}$ sites. Without going into the details of kinetics here, we focus on the cumulative production of $\mathrm{N}_{2}$ and equilibrium state of $\mathrm{NO}_{\mathrm{ad}}$ in the present discussion, aiming at assessing atomic structures and adsorption properties of the $\mathrm{Cu}$ sites 
in the zeolites. As previously suggested in Figure S8, the production of $\mathrm{N}_{2}$ from the lowtemperature interaction between $\mathrm{Cu}-\mathrm{ZSM} 5$ and $\mathrm{NO}$ can be attributed to the reaction ${ }^{76}$

$$
\left[\mathrm{Cu}^{+} \ldots \mathrm{Cu}^{+}\right]+\mathrm{N}_{2} \mathrm{O} \rightarrow[\mathrm{Cu}-\mathrm{O}-\mathrm{Cu}]^{2+}+\mathrm{N}_{2}
$$

where $\mathrm{N}_{2} \mathrm{O}$ can be derived from reaction (2) and (3). The total amount of $\mathrm{N}_{2}$ detected during the $\mathrm{NO}$ adsorption process increases with $P_{\mathrm{NO}}$, as more $\mathrm{N}_{2} \mathrm{O}$ is accessible for reaction (7) (Figures $5 \mathrm{c}$ ). A more interesting observation is the production of more $\mathrm{N}_{2}$ for the zeolites with lower $\mathrm{Si} / \mathrm{Al}$ ratios (Figures 5c). As indicated by the combination of reactions (3) and (7), the production of one $\mathrm{N}_{2}$ molecule involves two $\mathrm{Cu}$ dimers. $\mathrm{Cu}$ monomers are associated with reaction (6) and would not contribute to the production of $\mathrm{N}_{2}$ at the relatively low temperature $\left(80^{\circ} \mathrm{C}\right)$ employed here. Thereby the amount of $\mathrm{N}_{2}$ produced from the $\mathrm{NO}$ adsorption process is also quantitatively indicative of the abundance of $\mathrm{Cu}$ dimers in the zeolites. The correlation between $\mathrm{N}_{2}$ evolution and $\eta_{\mathrm{Cu} \cdot{ }^{\cdots} \mathrm{Cu}}$ exhibits a two-stage behavior (Figure S17). Fundamental understanding of these behaviors is obscured by the interweaving and competitive kinetics of reactions (6) and (7) during the interaction between $\mathrm{Cu}$-ZSM5 and $\mathrm{NO}$, but the more favorable production of $\mathrm{N}_{2}$ at higher abundance of $\mathrm{Cu}$ dimers is obviously an outcome of the higher probability of an $\mathrm{N}_{2} \mathrm{O}$ molecule generated from reaction (6) (or from $\mathrm{Cu}$ monomers in the process of forming $\left[\mathrm{Cu}-\mathrm{NO}_{3}\right]^{2+}$ ) to see another $\mathrm{Cu}$ dimer and get further reduced to $\mathrm{N}_{2}$ via reaction (7). It is conceivable that this probability becomes less sensitive to the rise of $\eta_{\mathrm{Cu} \cdots \mathrm{Cu}}$ at high abundance of $\mathrm{Cu}$ sites, given with the expectation that it approaches saturation when $\eta_{\mathrm{Cu} u \mathrm{Cu}}$ gets close to 1 .

The specific capacity of $\mathrm{NO}$ adsorption is found to be insensitive to the $\mathrm{Si} / \mathrm{Al}$ ratio, but to $P_{\text {NO }}$ (Figure $5 \mathrm{~d}$ ). For example, the specific capacity is consistently at $\sim 2.03 \mathrm{mmol} / \mathrm{g}_{\mathrm{Cu}}$ for the five types of zeolites under $800 \mathrm{ppm}$ of NO. Quantitative analysis of the NO adsorption capacities was performed in the framework of Ono-Kondo coordinates (see the Supplementary Information for 
more details) to derive the adsorption energy $\left(\Delta E_{\mathrm{NO}}\right)$ and "compression energy" $\left(\Delta E_{\text {comp }}\right) .{ }^{77}$ The latter term $\left(\Delta E_{\text {comp }}\right)$ describes the interaction between adjacent adsorbates. ${ }^{78,79}$ In the case of NO adsorption on $\mathrm{Cu}-\mathrm{ZSM} 5, \Delta E_{\text {comp }}$ is indicative of the apparent difference in free energy between $[\mathrm{Cu}-\mathrm{O}-\mathrm{Cu}(\mathrm{NO})]^{2+}$ and $[(\mathrm{NO}) \mathrm{Cu}-\mathrm{O}-\mathrm{Cu}(\mathrm{NO})]^{2+}$, namely the dimeric-Cu motifs with one or two NO adsorbates. Figure 5e shows the $P_{\mathrm{NO}}$-dependent adsorption capacities plotted in the generalized Ono-Kondo coordinates for the five types of zeolites (at $80^{\circ} \mathrm{C}$ ). $\Delta E_{\mathrm{NO}}$ derived from the intercepts are determined to be $\sim 33.5 \mathrm{kCal} / \mathrm{mol}$ for the $\mathrm{Cu}-\mathrm{ZSM} 5$, which matches well with the calculated values of $\sim 1.4 \mathrm{eV}(32.2 \mathrm{kCal} / \mathrm{mol})$ for $[\mathrm{Cu}-\mathrm{O}-\mathrm{Cu}(\mathrm{NO})]^{2+}$. The negative slopes indicate positive $\Delta E_{\text {comp. }}$ The derived $\Delta E_{\text {comp }}$ is dependent on the $\mathrm{Si} / \mathrm{Al}$ ratio and correspondingly $\eta_{\mathrm{Cu} \cdots \mathrm{Cu} \text {, which }}$ varies from $2.55 \mathrm{kCal} / \mathrm{mol}$ for Cu-ZSM5-100 to $7.73 \mathrm{kCal} / \mathrm{mol}$ for Cu-ZSM5-11.5.

As $\Delta E_{\text {comp }}$ derived from the $\mathrm{NO}$ adsorption isotherms represents a statistic average of all $\mathrm{Cu}$ sites and no competitive adsorption of $\mathrm{NO}$ is expected on monomeric $\mathrm{Cu}$ sites (which are occupied by nitrate adsorbates, eq. (6)), we expect that the Cu-ZSM5 with more abundant $\mathrm{Cu}$ dimers will be more subjected to adsorption compression. This inference is confirmed with the

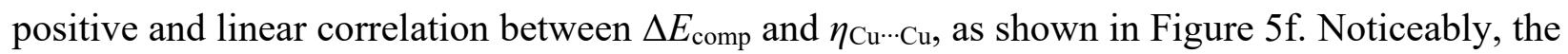
calculated difference in free energy between $[(\mathrm{NO}) \mathrm{Cu}-\mathrm{O}-\mathrm{Cu}]^{2+}$ and $[(\mathrm{NO}) \mathrm{Cu}-\mathrm{O}-\mathrm{Cu}(\mathrm{NO})]^{2+}$ is about $0.3 \mathrm{eV}$, which corresponds well to the upbound value of $\Delta E_{\text {comp }}(\sim 7-8 \mathrm{kCal} / \mathrm{mol})$ observed from the Ono-Kondo analysis of the $\mathrm{NO}_{\text {ad }}$ capacities and confirms the compression energy measurement as a viable means to evaluate the adsorption properties of the $\mathrm{Cu}$ sites within $\mathrm{Cu}$ ZSM5. Thereby $\Delta E_{\text {comp }}$ is a measurable descriptor of the adsorption properties for the $\mathrm{Cu}$ sites. Furthermore, a close view of their relationship finds slight deviation from the linear fitting, with $\Delta E_{\text {comp }}$ leveling off at high $\mathrm{Cu}$ dimer fractions. Such deviation indicates the presence of secondary effects, in addition to the population of dimers, contributing to the adsorption compression. It is 
likely that the $\mathrm{Cu} \cdots \mathrm{Cu}$ distance $e^{32,35,51,80}$ as well as the $\mathrm{Cu}-\mathrm{O}-\mathrm{Cu}$ bonding angle $\mathrm{e}^{26,36}$ have a weak dependence on the $\mathrm{Si} / \mathrm{Al}$ ratio, probably originating from the Boltzmann (instead of completely random) distribution of $\mathrm{Al}$ sites that has led to somewhat more favorable exposure of certain $\mathrm{Cu}$ dimer configurations (Table $\mathrm{S} 2)^{70,81,82}$ at low $\mathrm{Si} / \mathrm{Al}$ ratios and high $\mathrm{Cu}$ site densities.

Bridge adsorption analytics and reaction kinetics. In the above discussion, we have established $\eta_{\mathrm{Cu} \cdots \mathrm{Cu}}$ and $E_{\mathrm{comp}}$ as quantitative descriptors for the atomic structures and adsorption properties of Cu-ZSM5 by combining atomistic simulation, TPR, DFT calculations and NO titration. Now we show that this analytic information can be used to interpret the catalytic performance of $\mathrm{Cu}$-ZSM5 in NO decomposition reaction that takes place at elevated temperatures $\left(>300{ }^{\circ} \mathrm{C}\right)$.

For all the five types of Cu-ZSM5, the measured NO conversion exhibits a nonlinear behavior in dependence of temperature, with the maximum reached at $400-450{ }^{\circ} \mathrm{C}$ (Figure 6a). The drop of NO conversion at temperatures above $450{ }^{\circ} \mathrm{C}$ is not a result of equilibrium shift (Figure S18), neither due to catalyst deactivation (Figure S19). Throughout the temperature range (350$550{ }^{\circ} \mathrm{C}$ ) investigated here, the $\mathrm{NO}$ conversion decreases as $\mathrm{Si} / \mathrm{Al}$ ratio increases. At $450{ }^{\circ} \mathrm{C}$, the NO conversion varies from $85.2 \%$ on Cu-ZSM5- 11.5 to $46.6 \%$ on Cu-ZSM5-30, and to only $2.6 \%$ on Cu-ZSM5-100. Both $\mathrm{N}_{2}$ and $\mathrm{N}_{2} \mathrm{O}$ were detected as product, and the selectivity toward $\mathrm{N}_{2}$ increases with temperatures (Figure S20). The formation of $\mathrm{N}_{2}$ during $\mathrm{NO}$ decomposition can be via reactions (7) and

$$
\begin{aligned}
& {[\mathrm{Cu}-\mathrm{O}-\mathrm{Cu}]^{2+}+\mathrm{N}_{2} \mathrm{O} \rightarrow\left[\mathrm{Cu}-\mathrm{O}_{2}-\mathrm{Cu}\right]^{2+}+\mathrm{N}_{2}} \\
& {\left[\mathrm{Cu}-\mathrm{O}_{2}-\mathrm{Cu}\right]^{2+} \rightarrow\left[\mathrm{Cu}^{+} \cdot \mathrm{Cu}^{+}\right]+\mathrm{O}_{2}}
\end{aligned}
$$

where reactions (8) and $(9)^{34,35}$ are required for regeneration of the dimeric $\mathrm{Cu}$ sites (see Figure 3a for the scheme). Among the different catalysts, the zeolites with lower $\mathrm{Si} / \mathrm{Al}$ ratios have higher $\mathrm{N}_{2}$ 
selectivity, with Cu-ZSM5-11.5 achieving $99 \%$ at $450{ }^{\circ} \mathrm{C}$. It is further found that the zeolite with higher $\mathrm{Cu}$ dimer fraction gives higher specific rates (per $\mathrm{Cu}$ site) of $\mathrm{N}_{2}$ formation (Figure $6 \mathrm{~b}$ ). It can be concluded from these findings that the $\mathrm{Cu}$ dimers are active sites for the decomposition of $\mathrm{NO}$ to $\mathrm{N}_{2}$. This conclusion is further supported by the comparison of calculated NO decomposition pathways for the two types of $\mathrm{Cu}$ sites (Figure 3), which shows that the pathway toward $\mathrm{N}_{2}$ on monomers via reactions $(6)$ and

$$
\left[\mathrm{Cu}-\mathrm{NO}_{3}\right]^{+} \rightarrow[\mathrm{Cu}-\mathrm{NO}]^{+}+\mathrm{O}_{2}
$$

is much less favorable primarily due to the much higher reaction energy of (10) than (9). Noticeably, the $\mathrm{N}_{2}$ selectivity correlates well to the measured $\mathrm{N}_{2}$ evolution from the lowtemperature titration experiments (Figure 6c), expectable as the abundance of $\mathrm{Cu}$ dimers governs the pathway toward $\mathrm{N}_{2}$ in both cases.

Kinetic measurements were further performed on the Cu-ZSM5 catalysts at reduced loadings. The derived apparent rate constant $\left(k_{\text {app }}\right)$ for $\mathrm{N}_{2}$ formation exhibits a two-stage linear behavior in the Arrhenius plots (Figure 6d). In the low-temperature region (e.g., $T<400{ }^{\circ} \mathrm{C}$ for $\mathrm{Si} / \mathrm{Al}=11.5,20$ and 30), $k_{\text {app }}$ increases with temperature, indicating a positive activation energy $\left(E_{\mathrm{app}, 1}>0\right)$, whereas an opposite scenery for negative activation energy $\left(E_{\mathrm{app}, 2}<0\right)$ is discerned in the high-temperature region. The maximal $k_{\text {app }}$ is also reached at $\sim 400-450{ }^{\circ} \mathrm{C}$, suggesting that the volcano shape in the dependence of NO conversion on temperature (Figure 6a) is a result of kinetic effects. ${ }^{15,76,83}$ Similar to the observation in NO conversion, the Cu-ZSM5 with lower Si/Al ratios have larger $k_{\mathrm{app}}$, in line with the previous reports on $\mathrm{Cu}-\mathrm{ZSM} 5$ of the same $\mathrm{Si} / \mathrm{Al}$ ratio but different $\mathrm{Cu}$ exchange levels. ${ }^{37,84}$ According to the kinetic model reported by Modén et al. (see the Supplementary Information for more details), ${ }^{15}$ the two-stage behavior of Cu-ZSM5 is due to the interplay of NO decomposition (as shown in Figure 2a) and oxygen evolution pathways, with the 
latter likely limiting the reaction rate at relatively low temperatures (e.g., $\left.<400{ }^{\circ} \mathrm{C}\right)$ but becoming feasible at more elevated temperatures. The impact of $\mathrm{Cu}$ atomic structures on the reaction kinetics is better visualized by plotting $\ln \left(k_{\text {app }}\right)$ versus $\eta_{\mathrm{Cu} \text { ”. Cu }}$ (Figure 6e). The nearly linear relationships at both low and high temperatures underlines the above conclusion with $\mathrm{Cu}$ dimers being the active sites for decomposition of $\mathrm{NO}$ to $\mathrm{N}_{2}$. The different slopes, i.e., $7.0 @ 350{ }^{\circ} \mathrm{C}$ versus $3.7 @ 550{ }^{\circ} \mathrm{C}$, are indicative of the dissimilar weighing factors of the structure effects on the reaction kinetics, as the low-temperature reaction rate is limited by both NO conversion and oxygen evolution, both of which are more favorable on $\mathrm{Cu}$ dimers, whereas the high-temperature rate is only governed by NO conversion that becomes feasible on both dimers and monomers in this condition (e.g., at $>400$ $\left.{ }^{\circ} \mathrm{C}\right)$. We further found that both $E_{\mathrm{app}, 1}$ and $E_{\mathrm{app}, 2}$ correlate well to the adsorption property, $\Delta E_{\text {comp }}$, derived from the NO titration measurements (Figure 5f). The direct correlations of these energetic functions are indicative of and the experimental measure of the underlying scaling relationships among the free energies of various adsorbates and transition states involved in the NO decomposition reaction in dependence of the $\mathrm{Cu}$-motif atomic structures, namely more $\mathrm{Cu}$ dimers giving rise to more compression in the $\mathrm{NO}$ adsorption isotherm, reduced energy barriers for $\mathrm{NO}$ conversion and more favorable oxygen evolution (as compared to $\mathrm{Cu}$ monomers). Moreover, the better linear fitting for the correlation between $E_{a p p}$ and $\Delta E_{\text {comp }}$ than with $\eta_{\mathrm{Cu} \cdots \mathrm{Cu}}$ (Figure S21) suggest that the secondary structural effects (e.g., $\mathrm{Cu} \cdots \mathrm{Cu}$ distance ${ }^{32,35,78,79}$ and $\mathrm{Cu}-\mathrm{O}-\mathrm{Cu}$ bonding angle ${ }^{26,36}$ ), as captured by the adsorption compression energy measurements, also propagate to the catalytic reaction kinetics. The successful use of $\eta_{\mathrm{Cu} u \cdot \mathrm{Cu}}$ and $E_{\text {comp }}$ to interpret the catalytic performance of $\mathrm{Cu}$-ZSM5 thus bridged the low-temperature adsorption analytics and the hightemperature reaction kinetics. 
General applicability of $\eta_{\mathrm{Cu} u \cdot \mathrm{Cu}}$ and $\boldsymbol{E}_{\text {comp }}$ as descriptors. As discussed above, it is clear that $\eta_{\mathrm{Cu} \cdots \mathrm{Cu}}$ and $E_{\text {comp }}$ are valuable descriptors for both the structure and reactivity of Cu-ZSM5. In the following we further show that the established relationships can be generalized to other types of zeolites and reactions.

Similar to Cu-ZSM-5, copper-exchanged MOR and SSZ-13 are also important industrial catalysts that contain $\mathrm{Cu}$-dimer active sites. ${ }^{51,85-87}$ We have synthesized $\mathrm{Cu}-\mathrm{MOR}-10$ and $\mathrm{Cu}-$ SSZ13-11, both at full exchange $(\mathrm{Cu} / \mathrm{Al} \sim 0.5)$, for which $\eta_{\mathrm{Cu} u \cdot \mathrm{Cu}}$ is measured to be ca. $43 \%$ and $28 \%$, respectively (Figure S22 and Table S11), in consistent with literature results with similar $\mathrm{Cu}$ densities (Figure S23) ${ }^{88-90}$ DRIFTS analysis and chemical titration of the reactive adsorption of NO on these two types of copper-exchanged zeolites (Figure S24-S27 and Table S12-S14) confirm that they also follow the established linear relationships correlating the spectroscopic features (Figure 4e and Figure S28a), NO-adsorption compression energy (Figure 5f and Figure S28b) and the $\mathrm{Cu}$-dimer fraction. Moreover, catalytic studies for $\mathrm{NO}$ decomposition indicates that $\eta_{\mathrm{Cu} \cdot{ }^{\prime} \mathrm{Cu}}$ and $E_{\text {comp }}$ quantified for Cu-MOR and Cu-SSZ13 can also describe their reaction kinetics (Figure S29 and S30). The general applicability of these correlations for copper-exchanged zeolites confirms the established bridges between adsorption analytics and catalytic kinetics and is also in line with the expectation that they are characteristic of the $\mathrm{Cu}$-dimer motifs forming on aluminosilicate substrates.

In addition to $\mathrm{NO}$ decomposition, we have applied $\eta_{\mathrm{Cu}} \ldots \mathrm{Cu}$ and $E_{\mathrm{comp}}$ as descriptors to interpret the kinetics of methane-to-methanol (MTM) conversion. Cu-ZSM5 has been extensively studied for the MTM reaction. ${ }^{19,26,53,85,90,91}$ Although $[\mathrm{CuOCu}]^{2+}$ has been identified as the active sites for methane activation, ${ }^{42}$ quantitative correlation of the $\mathrm{Cu}$-dimer fraction (or number density) to the catalytic activity is few reported for MTM. Based on the average copper site densities recorded in 
the literature studies, ${ }^{19,26,91-93}$ we have estimated the corresponding copper dimer fractions and compression energies using the linear relationships established in Figures $2 \mathrm{~d}$ and $5 \mathrm{f}$ (see Table S15 and Figure S31). The estimated copper dimer fractions were confirmed by comparing them to the values determined in this study (Figure S32). Linear relationships are thus established between the MTM reactivity and $\eta_{\mathrm{Cu} \cdots \mathrm{Cu}}$ (Figure $7 \mathrm{a}$ ), as well as between the activation energy and $E_{\text {comp }}$ (Figure 7b). To validate the robustness and predictive capability of these relationships, we have further performed our own measurements of MTM on Cu-ZSM5-11.5 and Cu-ZSM5-20 (see the experimental methods in the Supplementary Information). These two catalysts produced 18.4 and $13.0 \mu \mathrm{mol}$ of methanol per gram of catalyst at $200{ }^{\circ} \mathrm{C}$, respectively (Figure S33). The corresponding activation energies are determined to be 77.7 and $80.0 \mathrm{~kJ} / \mathrm{mol}$ (Figure S34). Such values are in line with the previous reports with similar copper site densities (Figure S35) ${ }^{91,92}$ As shown in Figure 7, the measured catalytic performance falls onto the as-established linear relationships. It thus confirms the general applicability of $\eta_{\mathrm{Cu} u \cdot \mathrm{Cu}}$ and $E_{\text {comp }}$ as quantitative descriptors for the MTM reaction.

\section{CONCLUSION}

We have combined atomistic simulation, chemisorption and titration measurements to obtain reaction-relevant structural and property information of $\mathrm{Cu}$ exchanged ZSM5. The established descriptors such as $\eta_{\mathrm{Cu} \cdots \mathrm{Cu}}$ and $\Delta E_{\text {comp }}$ are validated to be applicable to Cu-ZSM5 prepared in this study and also other data reported in the literature. They are found to correlate well to the catalytic performance of the Cu-ZSM5 catalysts for NO decomposition. Our studies have established multiple linear correlations between the adsorption analytics and reaction kinetic parameters, which reflect the intrinsic scaling relationships governing the adsorption and catalytic properties 
of the metal sites within the zeolite. These relationships have further been generalized to understand the structure-property relationships of other metal-exchanged zeolites and interpretation of the catalytic performance of Cu-ZSM5 for the methane-to-methanol conversion. The quantitative descriptors and the corresponding correlations are thus believed to be valid for guiding the design and development of advanced catalytic materials for various reactions.

\section{ACKNOWLDEGEMENTS}

This work was supported by the Department of Energy, Advanced Research Projects AgencyEnergy (ARPA-E). PX and CW also acknowledge the support by the Petroleum Research Fund, American Chemical Society. AK acknowledges the use of computing resources provided by the National Energy Research Scientific Computing Center (NERSC), a U.S. Department of Energy Office of Science User Facility operated under Contract No. DE-AC02-05CH11231 and the Extreme Science and Engineering Discovery Environment (XSEDE), which is supported by National Science Foundation grant number ACI-1548562. 
Table 1. Bulk elemental analysis and BET Surface Area for $\mathrm{Cu}$-Zeolites with different $\mathrm{Si} / \mathrm{Al}$ ratios.

\begin{tabular}{|c|c|c|c|c|c|}
\hline $\mathrm{Si} / \mathrm{Al}$ & $\mathrm{Cu} / \mathrm{Al}$ & $\begin{array}{l}\text { Surface Area } \\
\qquad\left(\mathrm{m}^{2} \mathrm{~g}^{-1}\right)\end{array}$ & $\begin{array}{c}\text { Cu Loading } \\
(\mu \mathrm{mol} / \mathrm{g})\end{array}$ & $\begin{array}{l}\text { Cu Site Density } \\
\left(\times 1000 \AA^{-3}\right)\end{array}$ & $\begin{array}{c}\text { Average } \mathrm{Cu} \cdots \mathrm{Cu} \\
\text { Distance }(\AA)\end{array}$ \\
\hline 11.5 & 0.51 & 373 & 487.80 & 0.52 & 15.4 \\
\hline 20 & 0.51 & 373 & 336.74 & 0.36 & 17.4 \\
\hline 30 & 0.48 & 406 & 292.68 & 0.31 & 18.2 \\
\hline 50 & 0.49 & 385 & 154.21 & 0.17 & 22.6 \\
\hline 100 & 0.47 & 396 & 74.59 & 0.08 & 28.8 \\
\hline
\end{tabular}


(a)
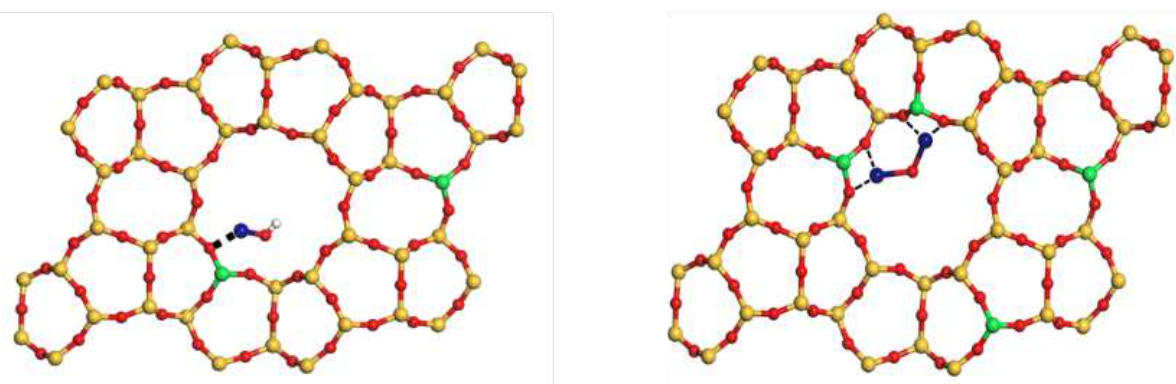

(b)

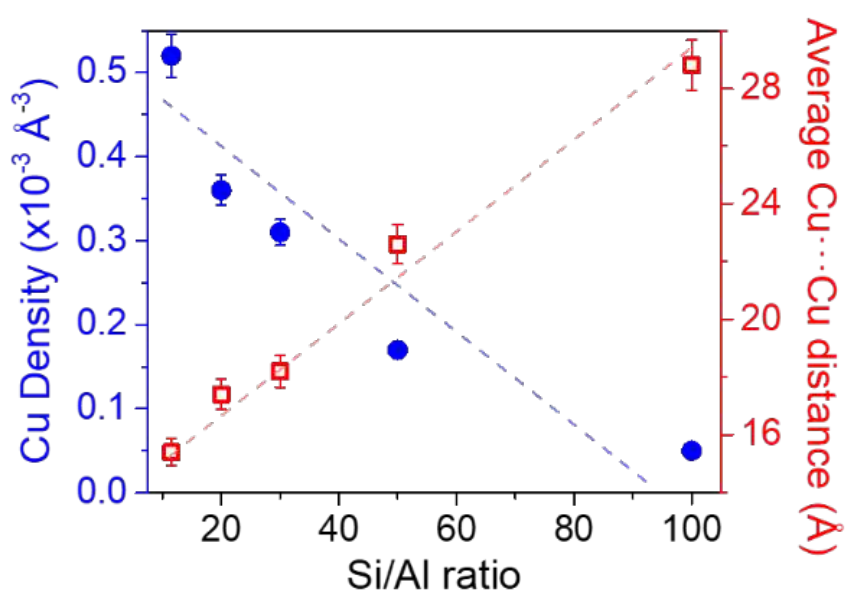

Figure 1. Graphical illustration and characterization of $\mathrm{Cu}$ sites in ZSM5. (a) Geometric models of a $\mathrm{Cu}$ monomer site (left) and an oxygen bridged $\mathrm{Cu}$ dimer site (right) in Cu-ZSM5. (b) Dependence of $\mathrm{Cu}$ density (per unit volume of the zeolite pore) and average $\mathrm{Cu}-\mathrm{Cu}$ distance on $\mathrm{Si} / \mathrm{Al}$ ratio in $\mathrm{Cu}-\mathrm{ZSM} 5$. 
(a)

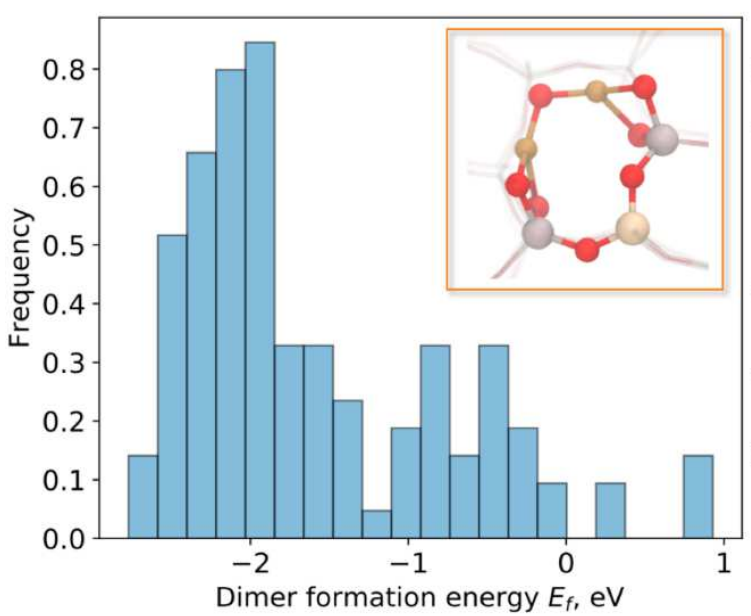

(c)

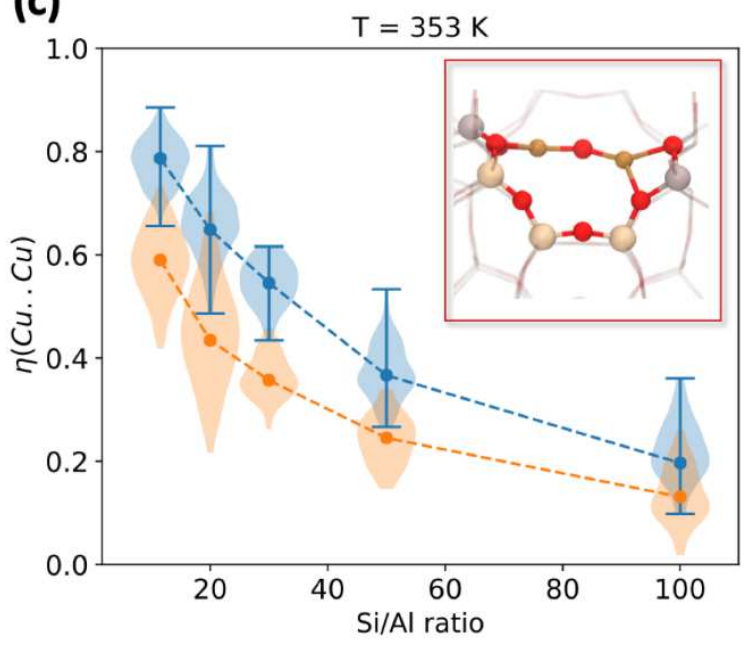

(b)
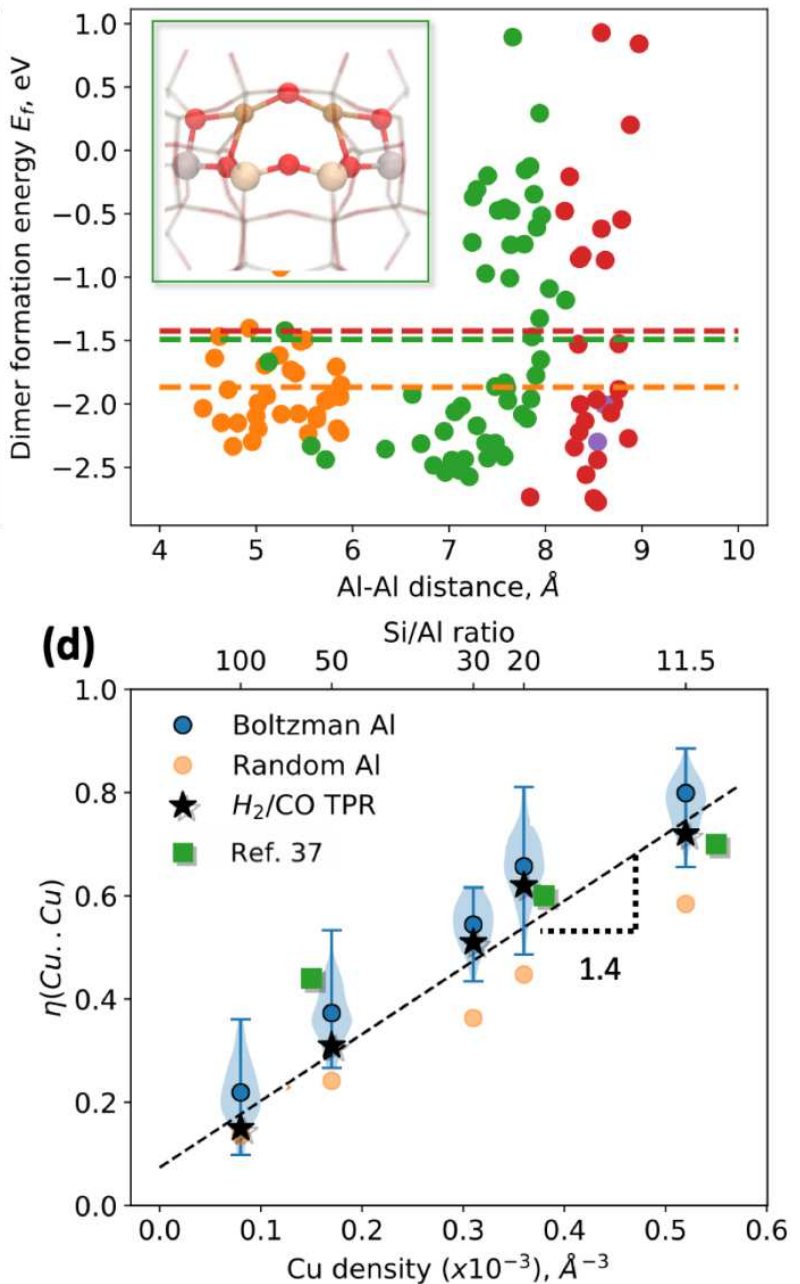

Figure 2. (a) Histogram showing the distribution of dimer formation energies $\left(E_{f}\right)$ for all possible $[\mathrm{CuOCu}]^{2+}$ dimers in MFI. (b) $\mathrm{E}_{\mathrm{f}}$ at different $\mathrm{Al}-\mathrm{Al}$ distances and $\# \mathrm{Si}$ atoms between the $2 \mathrm{Al}$ atoms: 1T (orange), 2T (green), 3T (red) and 4T (purple); the dotted lines show the average $\mathrm{E}_{\mathrm{f} .}$ (c) Fraction of $\mathrm{Cu}$ dimers in $\mathrm{MFI}, \eta(\mathrm{Cu} . . \mathrm{Cu})$ at $80{ }^{\circ} \mathrm{C}$ assuming a Boltzmann-weighted (blue) and random (orange) distribution of $\mathrm{Al}$ atoms. (d) Linear relationship between the $\mathrm{Cu}$ dimer fraction derived from DFT calculations (blue) and TPR measurements (black stars) with $\mathrm{Cu}$ density and Si/Al ratio. The experimental data from Ref. 37 (green squares) is consistent with our computational predictions. The insets in (a), (b) and (c) show the structures of the most favorable 1T, 2T and 3T dimer configuration in MFI. 


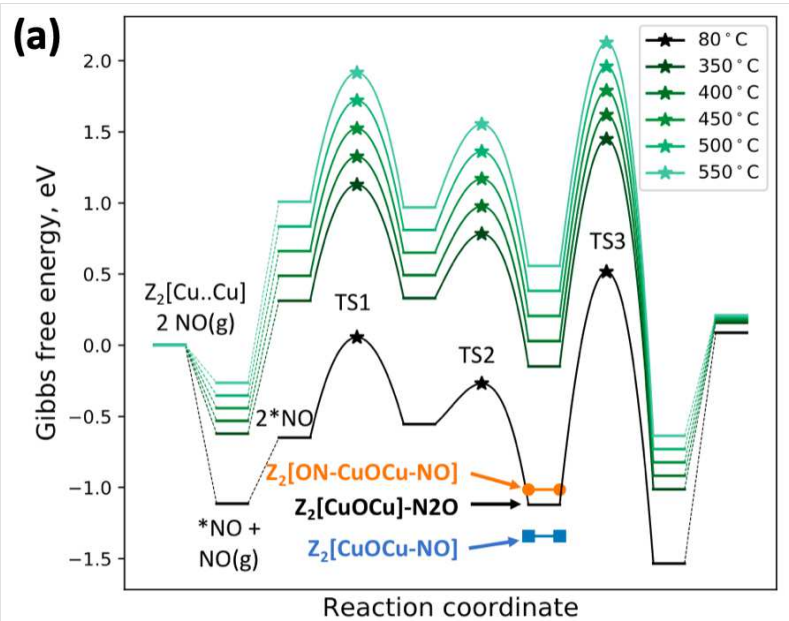

(b)

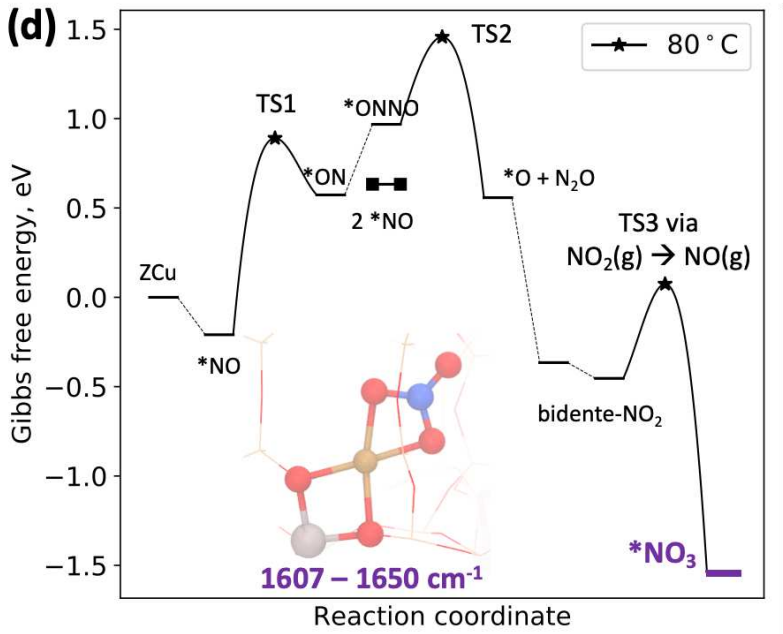

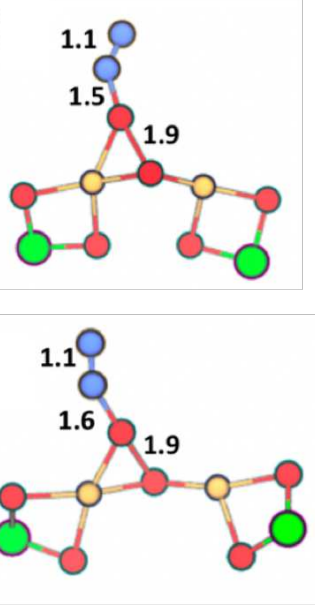

(c)
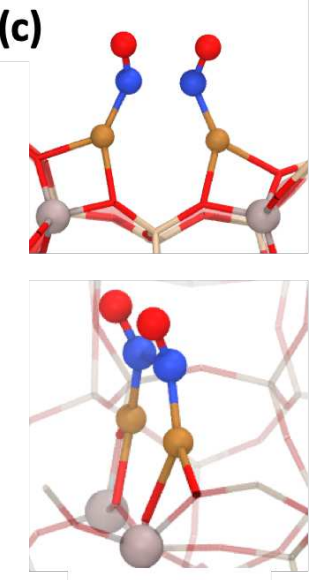

$1796 \mathrm{~cm}^{-1}$

(f)

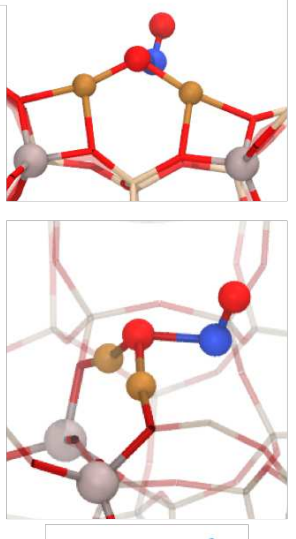

$1871 \mathrm{~cm}^{-1}$

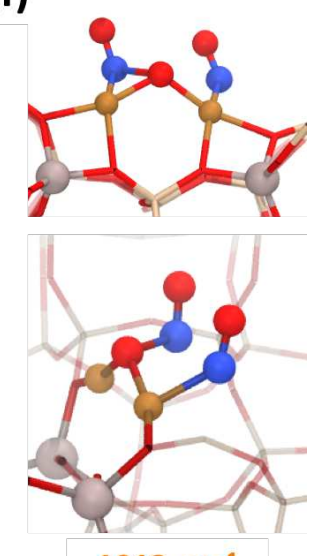

$1913 \mathrm{~cm}^{-1}$

Figure 3. (a) DFT calculated free energy diagrams at various temperatures for NO decomposition by $\mathrm{Cu}$ dimers in 1T-MFI; free energies of one and two NO bound dimers are shown in orange and blue, respectively. (b) The transition states for $\mathrm{N}_{2} \mathrm{O}$ decomposition for $1 \mathrm{~T}$ (upper) and 2T (lower) models (Red: O, Blue: N, Yellow: $\mathrm{Cu}$, Green: $\mathrm{Al}$ ), (c) - (f) structure model and vibrational frequencies for $\left[(\mathrm{ON}) \mathrm{Cu}^{+} \cdots \mathrm{Cu}^{+}(\mathrm{NO})\right],\left[\mathrm{Cu}-\mathrm{NO}_{3}\right]^{+}, \mathrm{NO}-[\mathrm{Cu}-\mathrm{O}-\mathrm{Cu}]^{2+}$ and $[(\mathrm{NO}) \mathrm{Cu}-\mathrm{O}-\mathrm{Cu}(\mathrm{NO})]^{2+}$, respectively (Red: O, Blue: N, Yellow: $\mathrm{Cu}$, Gray: $\mathrm{Al}$ ). The free energy diagram for the isolatedCu site is shown in (d) at $80{ }^{\circ} \mathrm{C}$. 

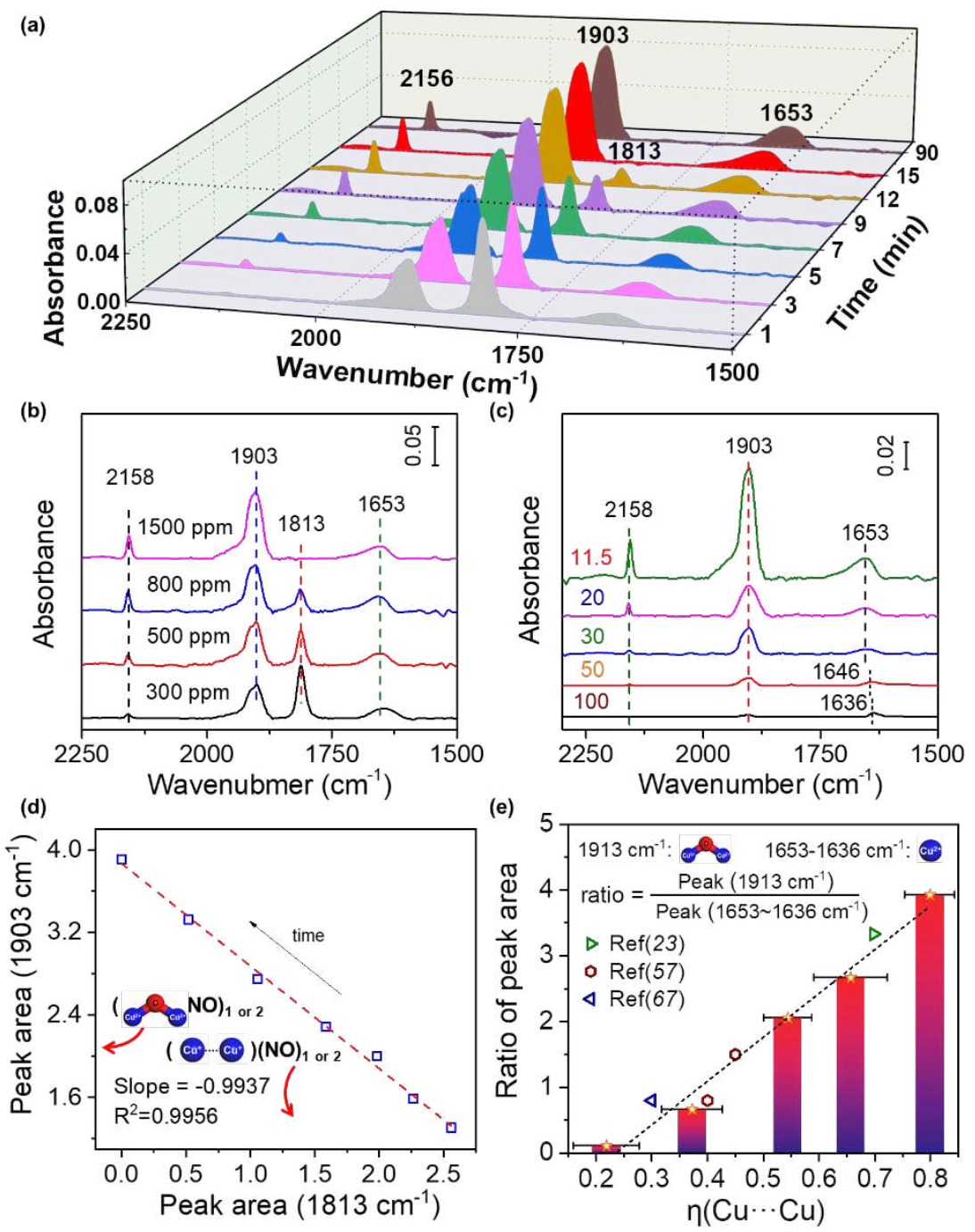

Figure 4. Characterization and quantification of $\mathrm{Cu}$ dimers in Cu-ZSM5 zeolites. (a) Time dependence DRIFTs of NO isothermal adsorption at $80{ }^{\circ} \mathrm{C}$ on $\mathrm{Cu}-\mathrm{ZSM} 5-11.5$ at $1500 \mathrm{ppm}$. (b) Pressure dependence DRIFTs of NO isothermal adsorption at $80{ }^{\circ} \mathrm{C}$ on $\mathrm{Cu}-\mathrm{ZSM}$ 5-11.5 at $15 \mathrm{~min}$. (c) DRIFTs of NO isothermal adsorption at $80^{\circ} \mathrm{C}$ on $\mathrm{Cu}$-ZSM5 with different $\mathrm{Si} / \mathrm{Al}$ ratios at 1500 ppm and 15 min. (d) Correlation of integrated peak areas of $1903 \mathrm{~cm}^{-1}$ peak and $1813 \mathrm{~cm}^{-1}$ peak in DRIFT spectra of NO isothermal adsorption at $80{ }^{\circ} \mathrm{C}$ and $1500 \mathrm{ppm}$ on $\mathrm{Cu}-\mathrm{ZSM} 5-11.5$ at different times. (e) Correlation of area ratios of $1903 \mathrm{~cm}^{-1}$ peak and $1813 \mathrm{~cm}^{-1}$ peak in DRIFT spectra of $\mathrm{NO}$ isothermal adsorption at $80{ }^{\circ} \mathrm{C}$ on $\mathrm{Cu}-\mathrm{ZSM} 5$ and $\mathrm{Cu}$ dimer fraction from DFT calculation and TPR measurements. 
(a)

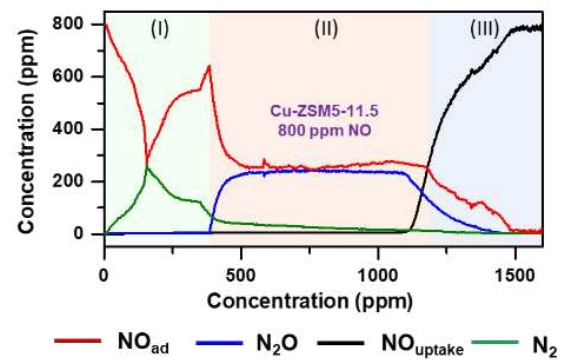

(c)
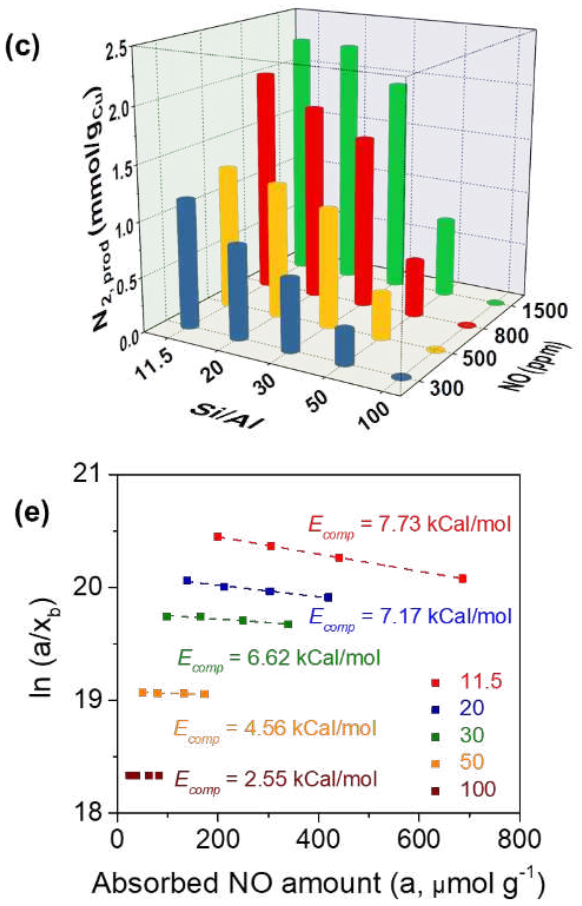

(b)

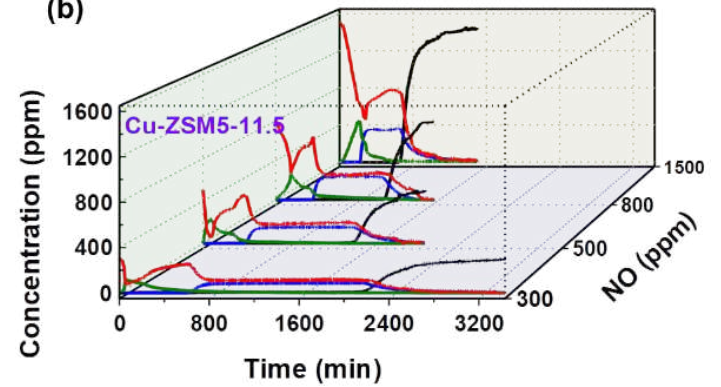

(d)

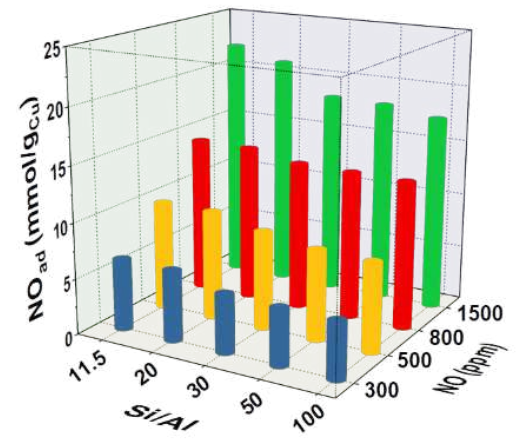

(f)

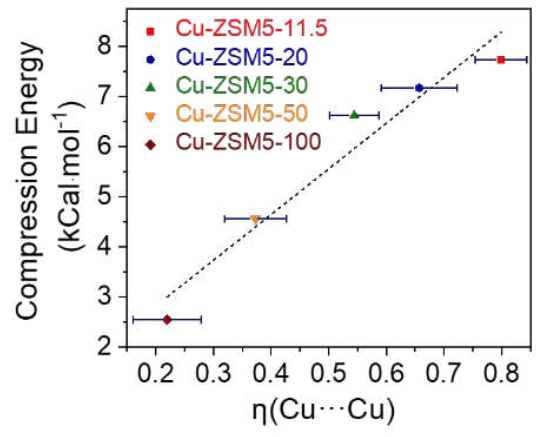

Figure 5. $\mathrm{NO}$ Isothermal adsorption profiles. $\left(\mathrm{NO}_{\text {ad: }}\right.$ red, $\mathrm{N}_{2}$,prod: green, $\mathrm{N}_{2} \mathrm{O}_{\text {prod: }}$ blue, $\mathrm{NO}_{\text {uptake: }}$ black) (a) Time dependent profiles of outlet concentrations of $\mathrm{NO}, \mathrm{N}_{2} \mathrm{O}$ and $\mathrm{N}_{2}$ during $\mathrm{NO}$ isothermal adsorptions at $80{ }^{\circ} \mathrm{C}$ with $800 \mathrm{ppm}$ of $\mathrm{NO}$ on Cu-ZSM5-11.5. (b) Time dependent plot of outlet concentrations of $\mathrm{NO}, \mathrm{N}_{2} \mathrm{O}$ and $\mathrm{N}_{2}$ during $\mathrm{NO}$ isothermal adsorptions at $80{ }^{\circ} \mathrm{C}$ with different pressures of $\mathrm{NO}$ for $\mathrm{Cu}-\mathrm{ZSM} 5-11.5$. (c) plot of $\mathrm{N}_{2}$ production per $\mathrm{Cu}$ site during $\mathrm{NO}$ isothermal adsorption at different NO pressures on the five Cu-ZSM5. (d) plots of adsorbed NO per $\mathrm{Cu}$ site during $\mathrm{NO}$ isothermal adsorption at different $\mathrm{NO}$ pressures on $\mathrm{Cu}-\mathrm{ZSM} 5$ zeolites. (e) Ono-Kondo plots for compression energies of Cu-ZSM5 zeolites. (f) Correlation of calculated compression energy and average $\mathrm{Cu}-\mathrm{Cu}$ distance in $\mathrm{Cu}-\mathrm{ZSM} 5$ zeolites. 
(a)

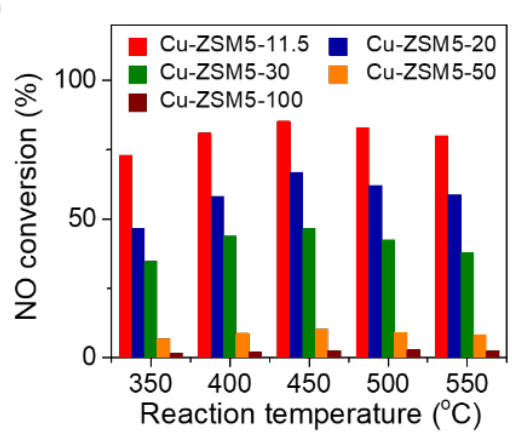

(d)

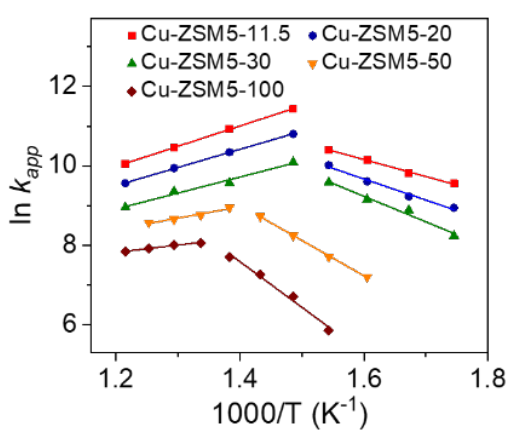

(b)

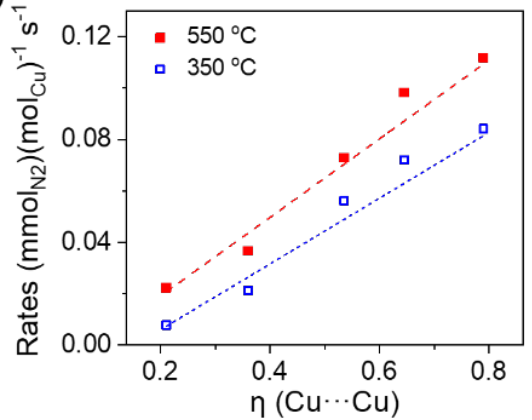

(e)

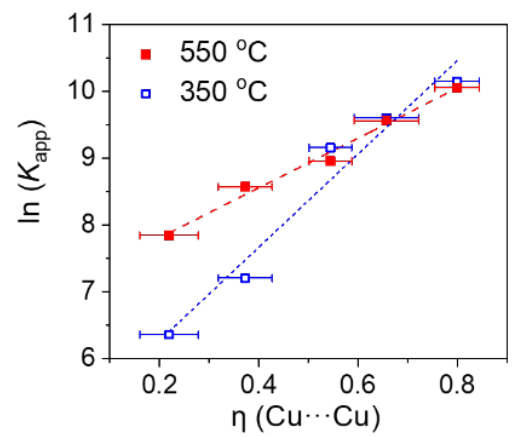

(c)

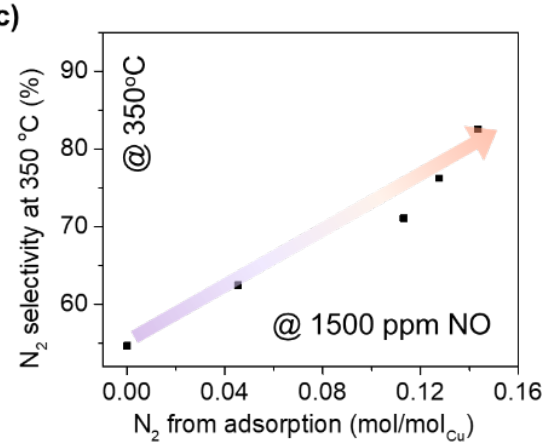

(f)

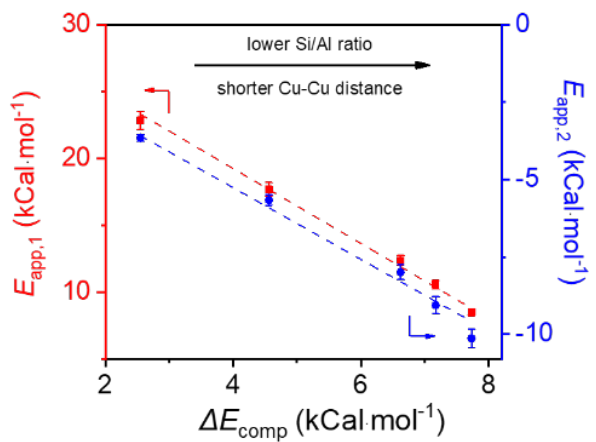

Figure 6. Catalytic performance and Kinetics of NO Decomposition. (a) Conversions of NO over different $\mathrm{Cu}$-ZSM5. (b) Correlations between rates of $\mathrm{N}_{2}$ at $350,550{ }^{\circ} \mathrm{C}$ and fractions of $\mathrm{Cu}$ dimers.

(c) Trends of $\mathrm{N}_{2}$ selectivity at 350 depending on $\mathrm{N}_{2}$ production during $\mathrm{NO}$ isothermal adsorptions at $80{ }^{\circ} \mathrm{C}$ with 1500 ppm of NO on Cu-ZSM5 zeolites. (d) Arrhenius plots for rate constants vs 1/T. (e) Correlations between $\ln \left(K_{\text {app }}\right)$ at $350,550{ }^{\circ} \mathrm{C}$ and fractions of $\mathrm{Cu}$ dimers fractions. (f) Correlation of apparent activation energies at low temperatures (red, left) and at high temperatures (blue, right) with compression energy derived from Ono-Kondo coordinates. 

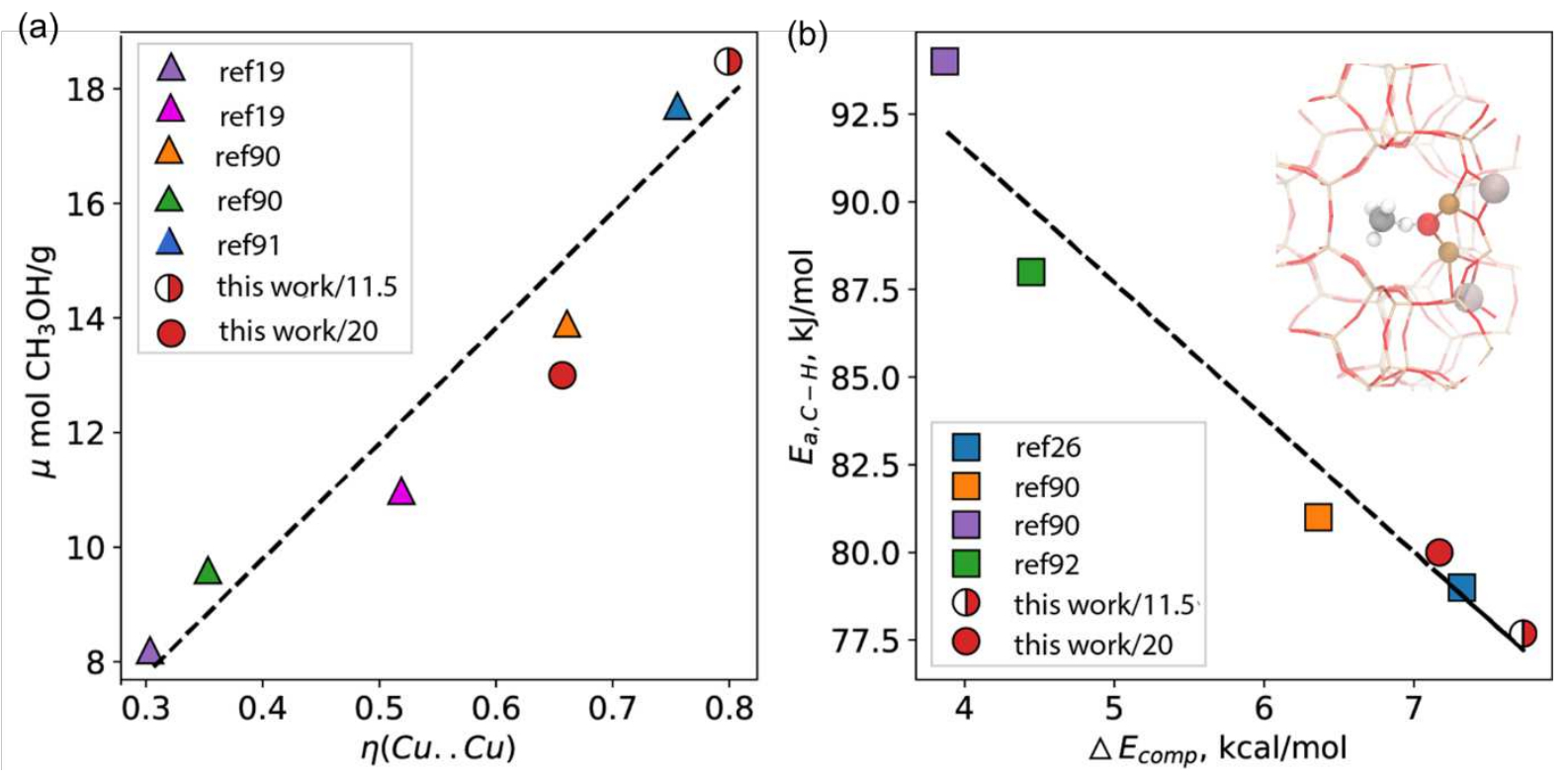

Figure 7. Catalytic study of methane to methanol by using $\mathrm{Cu}$-ZSM5 from the literature and this work. (a) Correlations between the methanol yields with $\mathrm{Cu}$ dimers fractions; (b) Correlation of apparent methane activation energies with compression energies. Hereby the $\mathrm{Cu}$ dimers fractions and compression energies are derived by fitting the $\mathrm{Cu}$ densities from literature into the scaling established in Figure 2d and Figure 5f. 


\section{References}

1 Weckhuysen, B. M. Snapshots of a working catalyst: possibilities and limitations of in situ spectroscopy in the field of heterogeneous catalysis. Chem. Commun., 97-110, (2002).

2 Yang, J. C., Small, M. W., Grieshaber, R. V. \& Nuzzo, R. G. Recent developments and applications of electron microscopy to heterogeneous catalysis. Chem. Soc. Rev. 41, 8179-8194, (2012).

3 Bordiga, S., Groppo, E., Agostini, G., van Bokhoven, J. A. \& Lamberti, C. Reactivity of Surface Species in Heterogeneous Catalysts Probed by In Situ X-ray Absorption Techniques. Chem. Rev. 113, 1736-1850, (2013).

4 Zaera, F. New advances in the use of infrared absorption spectroscopy for the characterization of heterogeneous catalytic reactions. Chem. Soc. Rev. 43, 7624-7663, (2014).

5 Wachs, I. E. \& Roberts, C. A. Monitoring surface metal oxide catalytic active sites with Raman spectroscopy. Chem. Soc. Rev. 39, 5002-5017, (2010).

6 Andersson, M. P., Bligaard, T., Kustov, A., Larsen, K. E., Greeley, J., Johannessen, T., Christensen, C. H. \& Norskov, J. K. Toward computational screening in heterogeneous catalysis: Pareto-optimal methanation catalysts. J. Catal. 239, 501-506, (2006).

7 Norskov, J. K., Bligaard, T., Rossmeisl, J. \& Christensen, C. H. Towards the computational design of solid catalysts. Nat. Chem. 1, 37-46, (2009).

8 Haneda, M. \& Hamada, H. Recent progress in catalytic NO decomposition. CR Chim. 19, 1254-1265, (2016).

9 Zhang, R. D., Liu, N., Lei, Z. G. \& Chen, B. H. Selective Transformation of Various NitrogenContaining Exhaust Gases toward $\mathrm{N}_{2}$ over Zeolite Catalysts. Chem. Rev. 116, 3658-3721, (2016).

10 Li, Y. J. \& Hall, W. K. Catalytic Decomposition of Nitric-Oxide over Cu-Zeolites. J. Catal. 129, 202215, (1991).

11 Grunert, W. H., N. W. Joyner, R. W. Shpiro, E. S. Siddiqui, M. R. H. \& Baeva, G. N. Structure, Chemistry, and Activity of Cu-Zsm-5 Catalysts for the Selective Reduction of Nox in the Presence of Oxygen. J. Phy. Chem. 98, 10832-10846, (1994).

12 Trout, B. L., Chakraborty, A. K. \& Bell, A. T. Analysis of the thermochemistry of NOx decomposition over CuZSM-5 based on quantum chemical and statistical mechanical calculations. J. Phy. Chem. 100, 17582-17592, (1996).

13 Lamberti, C. B., S. Salvalaggio, M. Spoto, G. Zecchina, A. Geobaldo, F. Vlaic, G. \& Bellatreccia, M. XAFS, IR, and UV-vis study of the Cu' environment in Cu'-ZSM-5. J. Phys. Chem. B 101, 344-360, (1997).

14 Schneider, W. F., Hass, K. C., Ramprasad, R. \& Adams, J. B. Density functional theory study of transformations of nitrogen oxides catalyzed by Cu-exchanged zeolites. J. Phys. Chem. B 102, 3692-3705, (1998).

15 Moden, B., Da Costa, P., Fonfe, B., Lee, D. K. \& Iglesia, E. Kinetics and mechanism of steady-state catalytic NO decomposition reactions on Cu-ZSM5. J. Catal. 209, 75-86, (2002).

16 Kuroda, Y. \& Iwamoto, M. Characterization of cuprous ion in high silica zeolites and reaction mechanisms of catalytic NO decomposition and specific $\mathrm{N}_{2}$ adsorption. Top. Catal. 28, 111-118, (2004).

17 Snyder, B. E. R., Bols, M. L., Schoonheydt, R. A., Sels, B. F. \& Solomon, E. I. Iron and Copper Active Sites in Zeolites and Their Correlation to Metalloenzymes. Chem. Rev. 118, 2718-2768, (2018).

18 Groothaert, M. H., Lievens, K., Leeman, H., Weckhuysen, B. M. \& Schoonheydt, R. A. An operando optical fiber UV-vis spectroscopic study of the catalytic decomposition of $\mathrm{NO}$ and $\mathrm{N}_{2} \mathrm{O}$ over $\mathrm{Cu}$ ZSM-5. J. Catal. 220, 500-512, (2003). 
Groothaert, M. H., Smeets, P. J., Sels, B. F., Jacobs, P. A. \& Schoonheydt, R. A. Selective oxidation of methane by the bis(mu-oxo)dicopper core stabilized on ZSM-5 and mordenite zeolites. J. Am. Chem. Soc. 127, 1394-1395, (2005).

20 Giordanino, F. V., P. N. R. Lundegaard, L. F. Stappen, F. N. Mossin, S. Beato, P. Bordiga, S. \& Lamberti, C. Characterization of Cu-exchanged SSZ-13: a comparative FTIR, UV-Vis, and EPR study with Cu-ZSM-5 and Cu-beta with similar Si/Al and Cu/Al ratios. Dalton. T. 42, 12741-12761, (2013). Palomino, G. T. F., P. Bordiga, S. Zecchina, A. Giamello, E. \& Lamberti, C. Oxidation states of copper ions in ZSM-5 zeolites: A multitechnique investigation. J. Phys. Chem. B 104, 4064-4073, (2000).

22 Beutel, T., Sarkany, J., Lei, G. D., Yan, J. Y. \& Sachtler, W. M. H. Redox chemistry of Cu/ZSM-5. J. Phys. Chem. 100, 845-851, (1996).

23 Konduru, M. V. \& Chuang, S. S. C. Investigation of adsorbate reactivity during NO decomposition over different levels of copper ion-exchanged ZSM-5 using in situ IR technique. J. Phys. Chem. B 103, 5802-5813, (1999).

24 Tortorelli, M., Chakarova, K., Lisi, L. \& Hadjiivanov, K. Disproportionation of associated $\mathrm{Cu}^{2+}$ sites in Cu-ZSM-5 to $\mathrm{Cu}^{+}$and $\mathrm{Cu}^{3+}$ and FTIR detection of $\mathrm{Cu}^{3+}(\mathrm{NO})_{x}(\mathrm{x}=1,2)$ species. J. Catal. 309, 376385, (2014).

25 Fanson, P. T., Stradt, M. W., Lauterbach, J. \& Delgass, W. N. The effect of Si/Al ratio and copper exchange level on isothermal kinetic rate oscillations for $\mathrm{N}_{2} \mathrm{O}$ decomposition over Cu-ZSM-5: a transient FTIR study. Appl. Catal. B 38, 331-347, (2002).

26 Woertink, J. S., Smeets, P. J., Groothaert, M. H., Vance, M. A., Sels, B. F., Schoonheydt, R. A. \& Solomon, E. I. A $\left[\mathrm{Cu}_{2} \mathrm{O}\right]^{2+}$ core in $\mathrm{Cu}-\mathrm{ZSM}-5$, the active site in the oxidation of methane to methanol. PNAS 106, 18908-18913, (2009).

27 Smeets, P. J. H., R. G. Woertink, J. S. Vanelderen, P. Schoonheydt, R. A. Sels, B. F. \& Solomon, E. I. Oxygen Precursor to the Reactive Intermediate in Methanol Synthesis by Cu-ZSM-5. J. Am. Chem. Soc. 132, 14736-14738, (2010).

28 Larsen, S. C., Aylor, A., Bell, A. T. \& Reimer, J. A. Electron-Paramagnetic-Resonance Studies of Copper lon-Exchanged ZSM-5. J. Phys. Chem. 98, 11533-11540, (1994).

29 Soria, J., Martinez-Arias, A., Martinez-Chaparro, A., Conesa, J. C. \& Schay, Z. Influence of the preparation method, outgassing treatment, and adsorption of $\mathrm{NO}$ and/or $\mathrm{O}_{2}$ on the $\mathrm{Cu}^{2+}$ species in Cu-ZSM-5: An EPR study. J. Catal. 190, 352-363, (2000).

30 Groothaert, M. H., Pierloot, K., Delabie, A. \& Schoonheydt, R. A. Identification of Cu(II) coordination structures in CU-ZSM-5, based on a DFT/ab initio assignment of the EPR spectra. Phys. Chem. Chem. Phys. 5, 2135-2144, (2003).

31 Neylon, M. K., Marshall, C. L. \& Kropf, A. J. In situ EXAFS analysis of the temperature-programmed reduction of Cu-ZSM-5. J. Am. Chem. Soc. 124, 5457-5465, (2002).

32 Groothaert, M. H., van Bokhoven, J. A., Battiston, A. A., Weckhuysen, B. M. \& Schoonheydt, R. A. Bis( $\mu$-oxo)dicopper in Cu-ZSM-5 and its role in the decomposition of NO: A combined in situ XAFS, UV-Vis-Near-IR, and kinetic study. J. Am. Chem. Soc. 125, 7629-7640, (2003).

33 Shido, T. Y., A. Inada, Y. Asakura, K. Nomura, M. \& Iwasawa, Y. Dispersive XAFS study on Cu and Mo species in zeolites during the catalyst preparation. Top. Catal. 18, 53-58, (2002).

34 Sajith, P. K., Shiota, Y. \& Yoshizawa, K. Role of Acidic Proton in the Decomposition of NO over Dimeric Cu(I) Active Sites in Cu-ZSM-5 Catalyst: A QM/MM Study. ACS Catal. 4, 2075-2085, (2014).

35 Moretti, G. F., G. Fierro, G. Lo Jacono, M. Morpurgo, S. \& Faticanti, M. Dimeric Cu(I) species in CuZSM-5 catalysts: the active sites for the NO decomposition. J. Catal. 232, 476-487, (2005).

36 Tsai, M. L. H., R. G. Vanelderen, P. Sels, B. F. Schoonheydt, R. A. \& Solomon, E. I. $\left[\mathrm{Cu}_{2} \mathrm{O}\right]^{2+}$ Active Site Formation in Cu-ZSM-5: Geometric and Electronic Structure Requirements for $\mathrm{N}_{2} \mathrm{O}$ Activation. J. Am. Chem. Soc. 136, 3522-3529, (2014). 
Da Costa, P. M., B. Meitzner, G. D. Lee, D. K. Iglesia, E. Spectroscopic and chemical characterization of active and inactive $\mathrm{Cu}$ species in NO decomposition catalysts based on Cu-ZSM5. Phys. Chem. Chem. Phys. 4, 4590-4601, (2002). Armor, J. N. Metal-exchanged zeolites as catalysts. Micropor. Mesopor. Mat. 22, 451-456, (1998). Brandenberger, S., Krocher, O., Tissler, A. \& Althoff, R. The State of the Art in Selective Catalytic Reduction of $\mathrm{NO}_{x}$ by Ammonia Using Metal-Exchanged Zeolite Catalysts. Catal. Rev. 50, 492-531, (2008).

40 Yang, S. T., Kim, J. \& Ahn, W. S. $\mathrm{CO}_{2}$ adsorption over ion-exchanged zeolite beta with alkali and alkaline earth metal ions. Micropor. Mesopor. Mat. 135, 90-94, (2010).

41 Hudson, M. R. Q., W. L. Mason, J. A. Fickel, D. W. Lobo, R. F. \& Brown, C. M. Unconventional, Highly Selective $\mathrm{CO}_{2}$ Adsorption in Zeolite SSZ-13. J. Am. Chem. Soc. 134, 1970-1973, (2012).

42 Ravi, M. S., V. L. Knorpp, A. J. Newton, M. A. Palagin, D. Pinar, A. B. Ranocchiari, M. van Bokhoven, J. A. Misconceptions and challenges in methane-to-methanol over transition-metal-exchanged zeolites. Nat. Catal. 2, 485-494, (2019).

43 Di lorio, J. R. \& Gounder, R. Controlling the Isolation and Pairing of Aluminum in Chabazite Zeolites Using Mixtures of Organic and Inorganic Structure-Directing Agents. Chem. Mater. 28, 2236-2247, (2016).

44 Kustova, M. Y., Rasmussen, S. B., Kustov, A. L. \& Christensen, C. H. Direct NO decomposition over conventional and mesoporous CU-ZSM-5 and CU-ZSM-11 catalysts: Improved performance with hierarchical zeolites. Appl. Catal. B 67, 60-67, (2006).

45 Xie, P. F., Ma, Z., Zhou, H. B., Huang, C. Y., Yue, Y. H., Shen, W., Xu, H. L., Hua, W. M. \& Gao, Z. Catalytic decomposition of $\mathrm{N}_{2} \mathrm{O}$ over Cu-ZSM-11 catalysts. Micropor. Mesopor. Mat. 191, 112-117, (2014).

46 Xie, P. F., Luo, Y. J., Ma, Z., Wang, L. Y., Huang, C. Y., Yue, Y. H., Hua, W. M. \& Gao, Z. CoZSM-11 catalysts for $\mathrm{N} 2 \mathrm{O}$ decomposition: Effect of preparation methods and nature of active sites. Appl. Catal. B 170, 34-42, (2015).

47 Gao, F., Kollar, M., Kukkadapu, R. K., Washton, N. M., Wang, Y. L., Szanyi, J. \& Peden, C. H. F. Fe/SSZ-13 as an NH3-SCR catalyst: A reaction kinetics and FTIR/Mossbauer spectroscopic study. Appl. Catal. B 164, 407-419, (2015).

48 Fanning, P. E. \& Vannice, M. A. A DRIFTS study of Cu-ZSM-5 prior to and during its use for $\mathrm{N}_{2} \mathrm{O}$ decomposition. J. Catal. 207, 166-182, (2002).

49 Dedecek, J., Balgova, V., Pashkova, V., Klein, P. \& Wichterlova, B. Synthesis of ZSM-5 Zeolites with Defined Distribution of Al Atoms in the Framework and Multinuclear MAS NMR Analysis of the Control of Al Distribution. Chem. Mater. 24, 3231-3239, (2012).

50 Borfecchia, E., Lomachenko, K. A., Giordanino, F., Falsig, H., Beato, P., Soldatov, A. V., Bordiga, S. \& Lamberti, C. Revisiting the nature of Cu sites in the activated Cu-SSZ-13 catalyst for SCR reaction. Chem. Sci. 6, 548-563, (2015).

51 Paolucci, C. K., I. Parekh, A. A. Li, S. C. Shih, A. J. Li, H. Di lorio, J. R. Albarracin-Caballero, J. D. Yezerets, A. Miller, J. T. Delgass, W. N. Ribeiro, F. H. Schneider, W. F. Gounder, R. Dynamic multinuclear sites formed by mobilized copper ions in NOx selective catalytic reduction. Science 357, 898-903, (2017).

52 Latimer, A. A. K., A. R. Aljama, H. Montoya, J. H. Yoo, J. S. Tsai, C. Abild-Pedersen, F. Studt, F. Norskov, J. K. Understanding trends in $\mathrm{C}-\mathrm{H}$ bond activation in heterogeneous catalysis. Nat. Mater. 16, 225-229, (2017).

53 Kulkarni, A. R., Zhao, Z. J., Siahrostami, S., Norskov, J. K. \& Studt, F. Cation-exchanged zeolites for the selective oxidation of methane to methanol. Catal. Sci. Technol. 8, 114-123, (2018). 

Oxidation of Methane to Methanol in Copper-Exchanged Mordenite. ACS Catal. 6, 3760-3766, (2016).

55 Mahyuddin, M. H., Staykov, A., Shiota, Y., Miyanishi, M. \& Yoshizawa, K. Roles of Zeolite Confinement and $\mathrm{Cu}-\mathrm{O}-\mathrm{Cu}$ Angle on the Direct Conversion of Methane to Methanol by $\left[\mathrm{Cu}_{2}(\mu-\right.$ O)] ${ }^{2+}$-Exchanged AEI, CHA, AFX, and MFI Zeolites. ACS Catal. 7, 3741-3751, (2017).

56 Mahyuddin, M. H., Staykov, A., Shiota, Y. \& Yoshizawa, K. Direct Conversion of Methane to Methanol by Metal-Exchanged ZSM-5 Zeolite (Metal = Fe, Co, Ni, Cu). ACS Catal. 6, 8321-8331, (2016).

57 Mahyuddin, M. H., Tanaka, T., Shiota, Y., Staykov, A. \& Yoshizawa, K. Methane Partial Oxidation over $\left[\mathrm{Cu}_{2}(\mu-\mathrm{O})\right]^{2+}$ and $\left[\mathrm{Cu}_{3}(\mu-\mathrm{O})_{3}\right]^{2+}$ Active Species in Large-Pore Zeolites. ACS Catal. 8, 1500-1509, (2018).

58 Larsen, A. H. M., J. J. Blomqvist, J. Castelli, I. E. Christensen, R. Dulak, M. Friis, J. Groves, M. N. Hammer, B. Hargus, C. Hermes, E. D. Jennings, P. C. Jensen, P. B. Kermode, J. Kitchin, J. R. Kolsbjerg, E. L. Kubal, J. Kaasbjerg, K. Lysgaard, S. Maronsson, J. B. Maxson, T. Olsen, T. Pastewka, L. Peterson, A. Rostgaard, C. Schiotz, J. Schutt, O. Strange, M. Thygesen, K. S. Vegge, T. Vilhelmsen, L. Walter, M. Zeng, Z. H. Jacobsen, K. W. The atomic simulation environment-a Python library for working with atoms. J. Phys.: Condens. Matter. 29, (2017).

59 Knott, B. C., Nimlos, C. T., Robichaud, D. J., Nimlos, M. R., Kim, S. \& Gounder, R. Consideration of the Aluminum Distribution in Zeolites in Theoretical and Experimental Catalysis Research. ACS Catal. 8, 770-784, (2018).

60 Wang, S., He, Y., Jiao, W. Y., Wang, J. G. \& Fan, W. B. Recent experimental and theoretical studies on Al siting/acid site distribution in zeolite framework. Curr. Opin. Chem. Eng. 23, 146-154, (2019).

61 Dedecek, J., Tabor, E. \& Sklenak, S. Tuning the Aluminum Distribution in Zeolites to Increase their Performance in Acid-Catalyzed Reactions. Chemsuschem 12, 556-576, (2019).

62 Itadani, A. S., H. Tanaka, M. Mori, T. Nagao, M. Kuroda, Y. New information related to the adsorption model of $\mathrm{N}_{2}$ on CuMFI at room temperature. J. Phys. Chem. C111, 16701-16705, (2007). Henriques, C., Ribeiro, M. F., Abreu, C., Murphy, D. M., Poignant, F., Saussey, J. \& Lavalley, J. C. An FT-IR study of NO adsorption over Cu-exchanged MFI catalysts: Effect of Si/Al ratio, copper loading and catalyst pre-treatment. Appl. Catal. B 16, 79-95, (1998).

64 Kosinov, N., Liu, C., Hensen, E. J. M. \& Pidko, E. A. Engineering of Transition Metal Catalysts Confined in Zeolites. Chem. Mater. 30, 3177-3198, (2018).

65 Agarwal, N. F., S. J. McVicker, R. U. Althahban, S. M. Dimitratos, N. He, Q. Morgan, D. J. Jenkins, R. L. Willock, D. J. Taylor, S. H. Kiely, C. J. Hutchings, G. J. Aqueous Au-Pd colloids catalyze selective $\mathrm{CH}_{4}$ oxidation to $\mathrm{CH}_{3} \mathrm{OH}$ with $\mathrm{O}_{2}$ under mild conditions. Science 358, 223-226, (2017).

66 Vanelderen, P. S., B. E. R. Tsai, M. L. Hadt, R. G. Vancauwenbergh, J. Coussens, O. Schoonheydt, R. A. Sels, B. F. Solomon, E. I. Spectroscopic Definition of the Copper Active Sites in Mordenite: Selective Methane Oxidation. J. Am. Chem. Soc. 137, 6383-6392, (2015).

67 Morpurgo, S., Moretti, G. \& Bossa, M. A computational study on the mechanism of NO decomposition catalyzed by Cu-ZSM-5: A comparison between single and dimeric $\mathrm{Cu}+$ active sites. J. Mole. Catal. a Chem. 358, 134-144, (2012).

68 Morpurgo, S. A DFT study on the mechanism of NO decomposition catalyzed by short-distance $\mathrm{Cu}(\mathrm{I})$ pairs in Cu-ZSM-5. Mole. Catal. 434, 96-105, (2017).

69 Schneider, W. F., Hass, K. C., Ramprasad, R. \& Adams, J. B. First-principles analysis of elementary steps in the catalytic decomposition of NO by Cu-exchanged zeolites. J. Phys. Chem. B 101, 43534357, (1997).

70 Sajith, P. K., Shiota, Y. \& Yoshizawa, K. Role of Acidic Proton in the Decomposition of NO over Dimeric Cu(I) Active Sites in Cu-ZSM-5 Catalyst: A QM/MM Study. ACS CataL. 4, 2075-2085, (2014). 
Ganemi, B., Bjornbom, E. \& Paul, J. Conversion and in situ FTIR studies of direct NO decomposition over Cu-ZSM5. Appl. Catal. B. 17, 293-311, (1998).

72 Hadjiivanov, K. I. Identification of neutral and charged $\mathrm{N}_{\mathrm{x}} \mathrm{O}_{\mathrm{y}}$ surface species by IR spectroscopy. Catal. Rev. 42, 71-144, (2000).

73 Izquierdo, R., Rodriguez, L. J., Anez, R. \& Sierraalta, A. Direct catalytic decomposition of NO with Cu-ZSM-5: A DFT-ONIOM study. J. Mole. Catal. A Chem. 348, 55-62, (2011).

74 Kuroda, Y., Kumashiro, R., Yoshimoto, T. \& Nagao, M. Characterization of active sites on copper ion-exchanged ZSM-5-type zeolite for NO decomposition reaction. Phys. Chem. Chem. Phys. 1, 649-656, (1999).

75 Rice, M. J., Chakraborty, A. K. \& Bell, A. T. Al next nearest neighbor, ring occupation, and proximity statistics in ZSM-5. J. Catal. 186, 222-227, (1999).

76 Lee, D. K. Thermodynamic features of the Cu-ZSM-5 catalyzed NO decomposition reaction. Korean. J. Chem. Eng. 23, 547-554, (2006).

77 Aranovich, G. L. D., M. D. Phase loops in density-functional-theory calculations of adsorption in nanoscale pores. Phys. Rev. E 60, 5552-5560, (1999).

78 Aranovich, G. L. \& Donohue, M. D. Adsorption compression: An important new aspect of adsorption behavior and capillarity. Langmuir 19, 2722-2735, (2003).

79 Sumanatrakul, P., Abaza, S., Aranovich, G. L., Sangwichien, C. \& Donohue, M. D. Pattern of adsorption isotherms in Ono-Kondo coordinates. J. Colloid Interface Sci. 368, 427-433, (2012).

80 Smeets, P. J. G., M. H. van Teeffelen, R. M. Leeman, H. Hensen, E. J. M. Schoonheydt, R. A. Direct $\mathrm{NO}$ and $\mathrm{N}_{2} \mathrm{O}$ decomposition and $\mathrm{NO}$-assisted $\mathrm{N}_{2} \mathrm{O}$ decomposition over Cu-zeolites: Elucidating the influence of the $\mathrm{Cu}$-Cu distance on oxygen migration. J. Catal. 245, 358-368, (2007).

81 Beale, A. M. G., F. Lezcano-Gonzalez, I. Peden, C. H. F. Szanyi, J. Recent advances in automotive catalysis for NOx emission control by small-pore microporous materials. Chem. Soc. Rev. 44, 73717405, (2015).

82 Teraishi, K. I., M. Irisawa, J. Kume, M. Takahashi, Y. Nakano, T. Nakamura, H. Miyamoto, A. Active site structure of Cu/ZSM-5: Computational study. J. Phys. Chem. B 101, 8079-8085, (1997).

83 Schay, Z., Knozinger, H., Guczi, L. \& Pal-Borbely, G. On the mechanism of NO decomposition on Cu-ZSM-5 catalysts. Appl. Catal. B 18, 263-271, (1998).

84 Iwamoto, M. Y., H. Tanda, K. Mizuno, N. Mine, Y. Kagawa, S. Removal of Nitrogen Monoxide through a Novel Catalytic Process .1. Decomposition on Excessively Copper-lon Exchanged ZSM-5 Zeolites. J. Phys. Chem. 95, 3727-3730, (1991).

85 Sushkevich, V. L. P., D. Ranocchiari, M. van Bokhoven, J. A. Selective anaerobic oxidation of methane enables direct synthesis of methanol. Science 356, 523-527, (2017).

86 Li, Y. L., L. Yu, J. H. Applications of Zeolites in Sustainable Chemistry. Chem 3, 928-949, (2017).

87 Dusselier, M. \& Davis, M. E. Small-Pore Zeolites: Synthesis and Catalysis. Chem. Rev. 118, 52655329, (2018).

88 Verma, A. A. B., S. A. Anggara, T. Paolucci, C. Parekh, A. A. Kamasamudram, K. Yezerets, A. Miller, J. T. Delgass, W. N. Schneider, W. F. Ribeiro, F. H. NO oxidation: A probe reaction on Cu-SSZ-13. J. Catal. 312, 179-190, (2014).

89 Godiksen, A. V., P. Rasmussen, S. Mossin, S. Identification and Quantification of Copper Sites in Zeolites by Electron Paramagnetic Resonance Spectroscopy. Top. Catal. 60, 13-29, (2017).

90 Pappas, D. K. M., A. Dyballa, M. Kvande, K. Teketel, S. Lomachenko, K. A. Baran, R. Glatzel, P. Arstad, B. Berlier, G. Lamberti, C. Bordiga, S. Olsbye, U. Svelle, S. Beato, P. Borfecchia, E. The Nuclearity of the Active Site for Methane to Methanol Conversion in Cu-Mordenite: A Quantitative Assessment. J. Am. Chem. Soc. 140, 15270-15278, (2018). 
91 Narsimhan, K., Iyoki, K., Dinh, K. \& Roman-Leshkov, Y. Catalytic Oxidation of Methane into Methanol over Copper-Exchanged Zeolites with Oxygen at Low Temperature. ACS Cent. Sci. 2, 424-429, (2016).

92 Tomkins, P. et al. Isothermal Cyclic Conversion of Methane into Methanol over Copper-Exchanged Zeolite at Low Temperature. Angew.Chem. Int. Ed. 55, 5467-5471, (2016).

93 Yumura, T., Hirose, Y., Wakasugi, T., Kuroda, Y. \& Kobayashi, H. Roles of Water Molecules in Modulating the Reactivity of Dioxygen-Bound Cu-ZSM-5 toward Methane: A Theoretical Prediction. ACS Catal. 6, 2487-2495, (2016). 
Figures

(a)
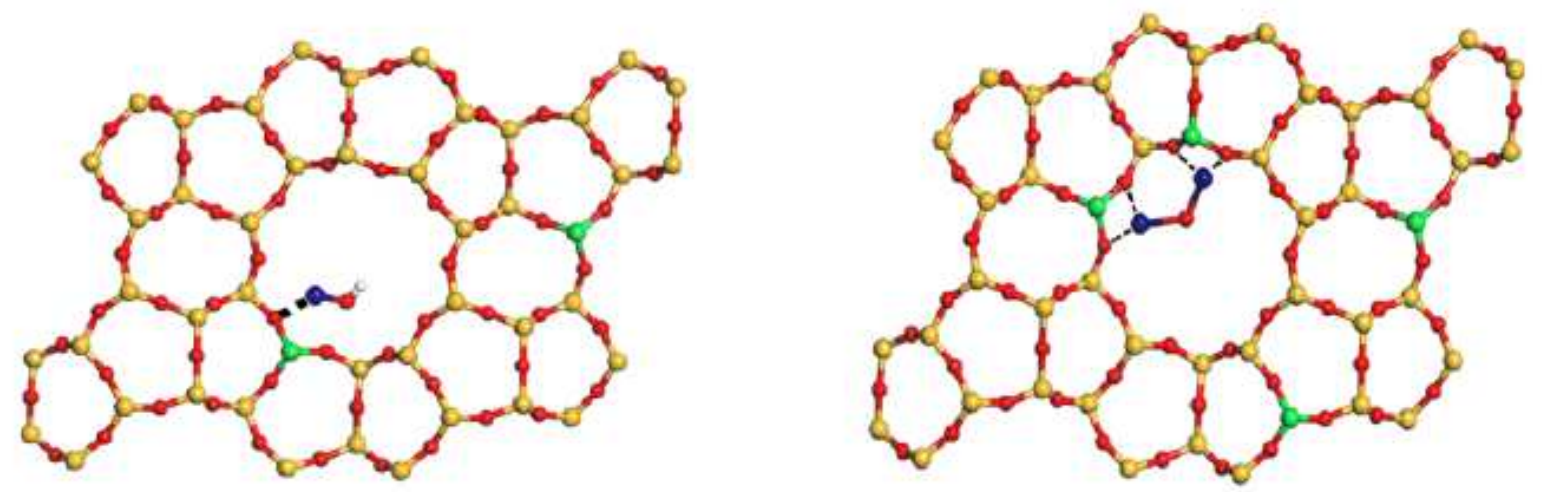

(b)

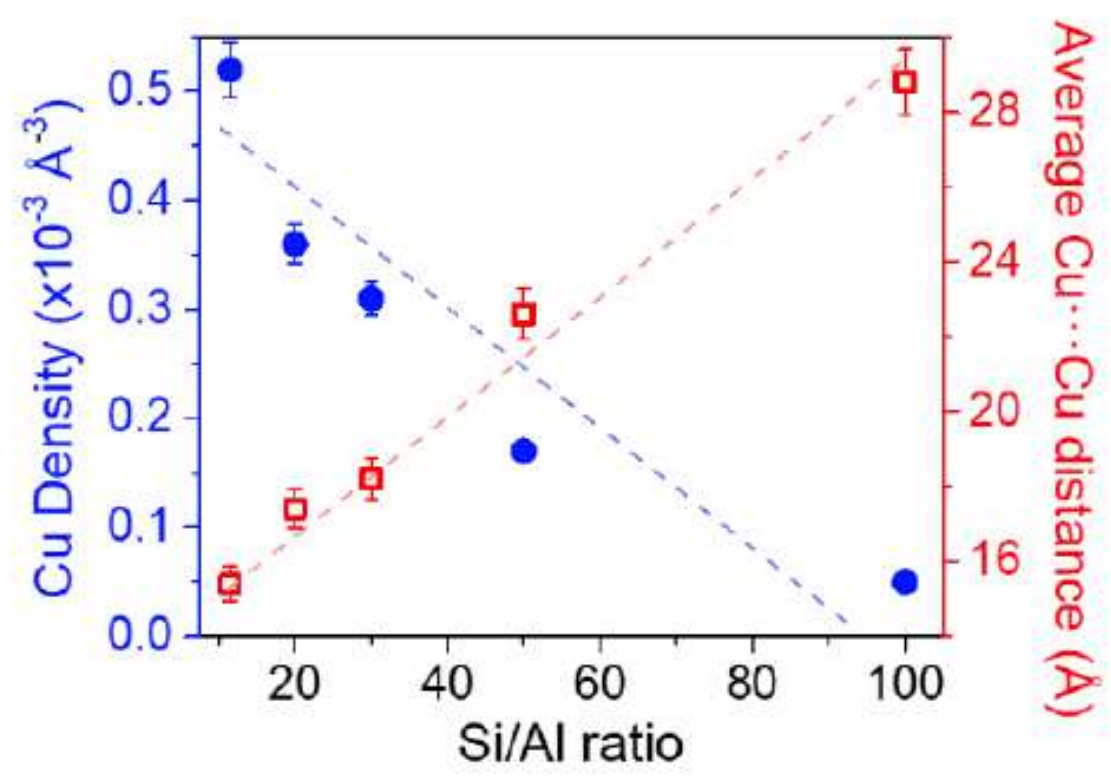

Figure 1

Graphical illustration and characterization of Cu sites in ZSM5. (a) Geometric models of a Cu monomer site (left) and an oxygen bridged Cu dimer site (right) in Cu-ZSM5. (b) Dependence of Cu density (per unit volume of the zeolite pore) and average Cu-Cu distance on Si/Al ratio in Cu-ZSM5. 
(a)
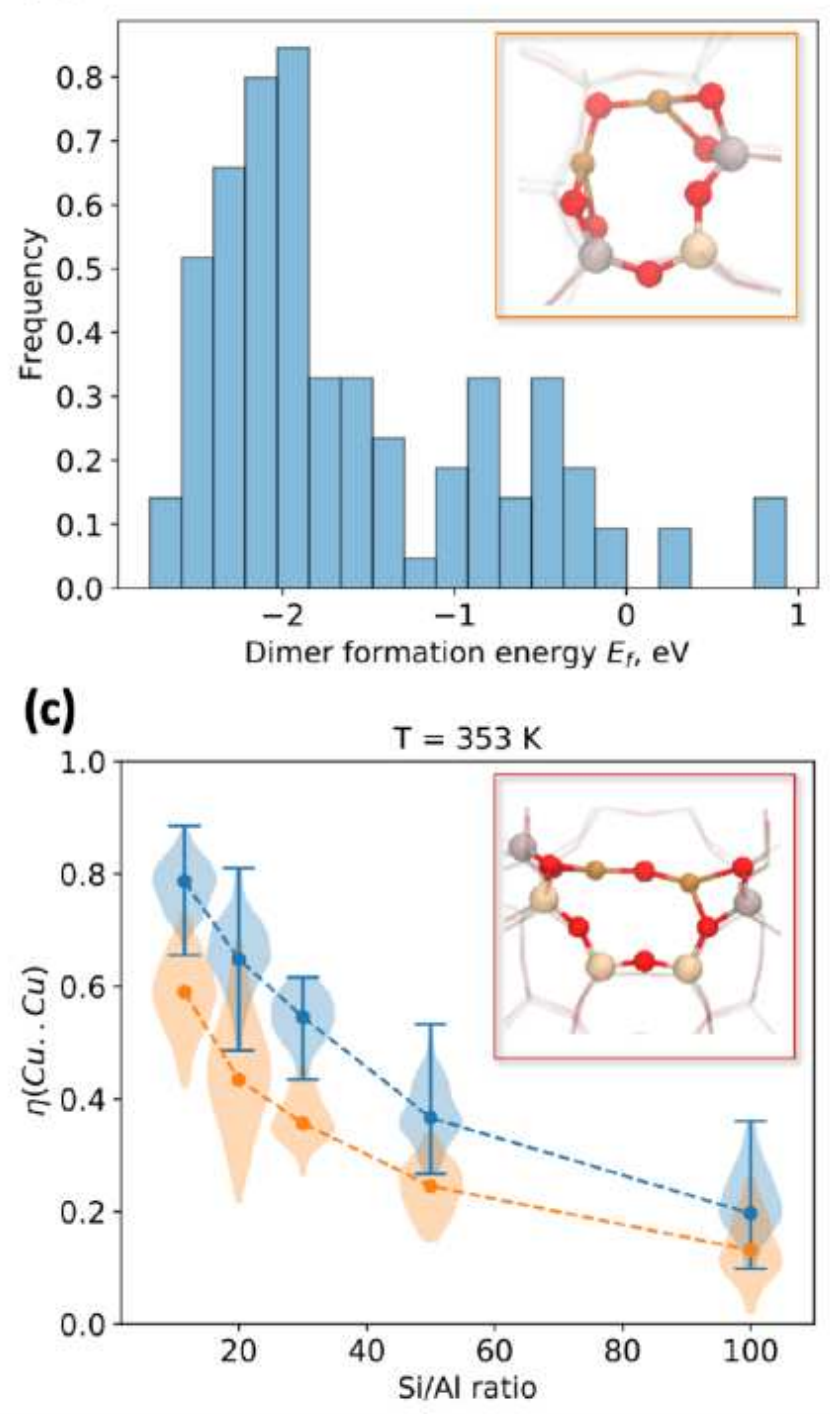

(b)

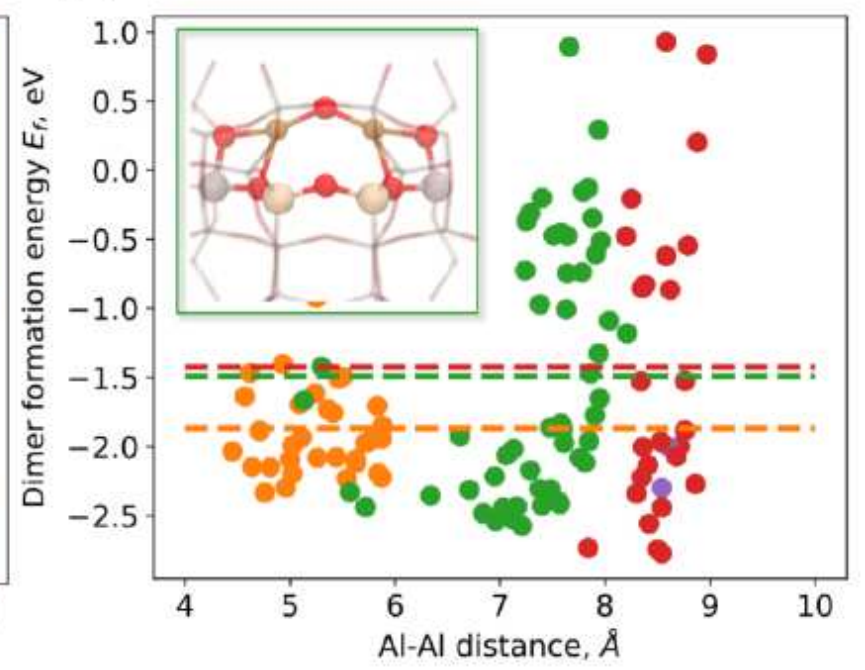

(d)

Si/Al ratio

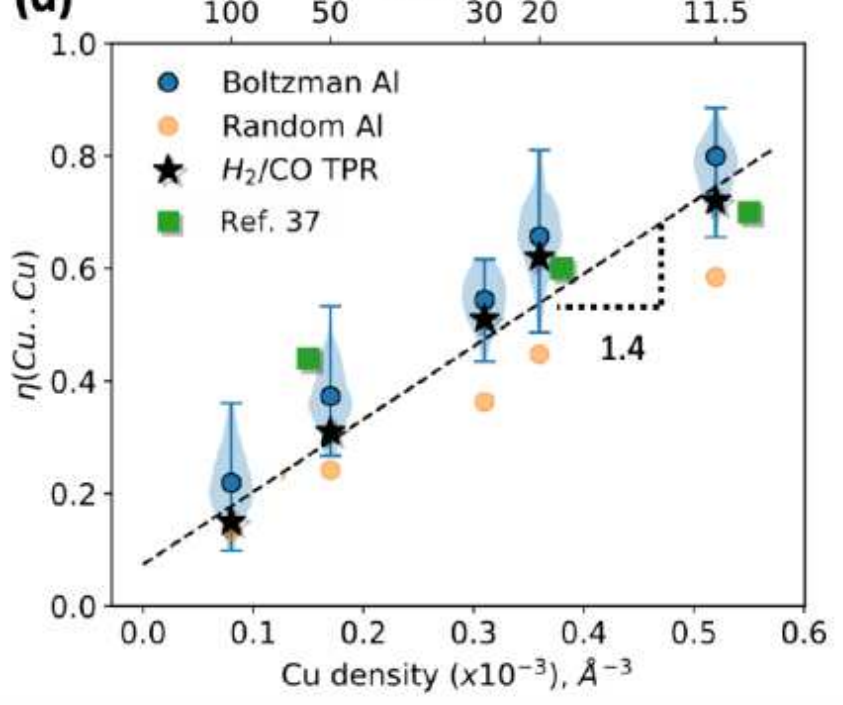

Figure 2

(a) Histogram showing the distribution of dimer formation energies (Ef) for all possible [CuOCu]2+ dimers in MFI. (b) Ef at different Al-Al distances and \#Si atoms between the 2Al atoms: 1T (orange), 2T (green), $3 \mathrm{~T}$ (red) and 4T (purple); the dotted lines show the average Ef. (c) Fraction of $\mathrm{Cu}$ dimers in MFI, $\eta(\mathrm{Cu} . . \mathrm{Cu})$ at $80^{\circ} \mathrm{C}$ assuming a Boltzmann-weighted (blue) and random (orange) distribution of Al atoms. (d) Linear relationship between the $\mathrm{Cu}$ dimer fraction derived from DFT calculations (blue) and TPR measurements (black stars) with Cu density and Si/Al ratio. The experimental data from Ref. 37 (green squares) is consistent with our computational predictions. The insets in (a), (b) and (c) show the structures of the most favorable 1T, $2 \mathrm{~T}$ and $3 \mathrm{~T}$ dimer configuration in MFI. 

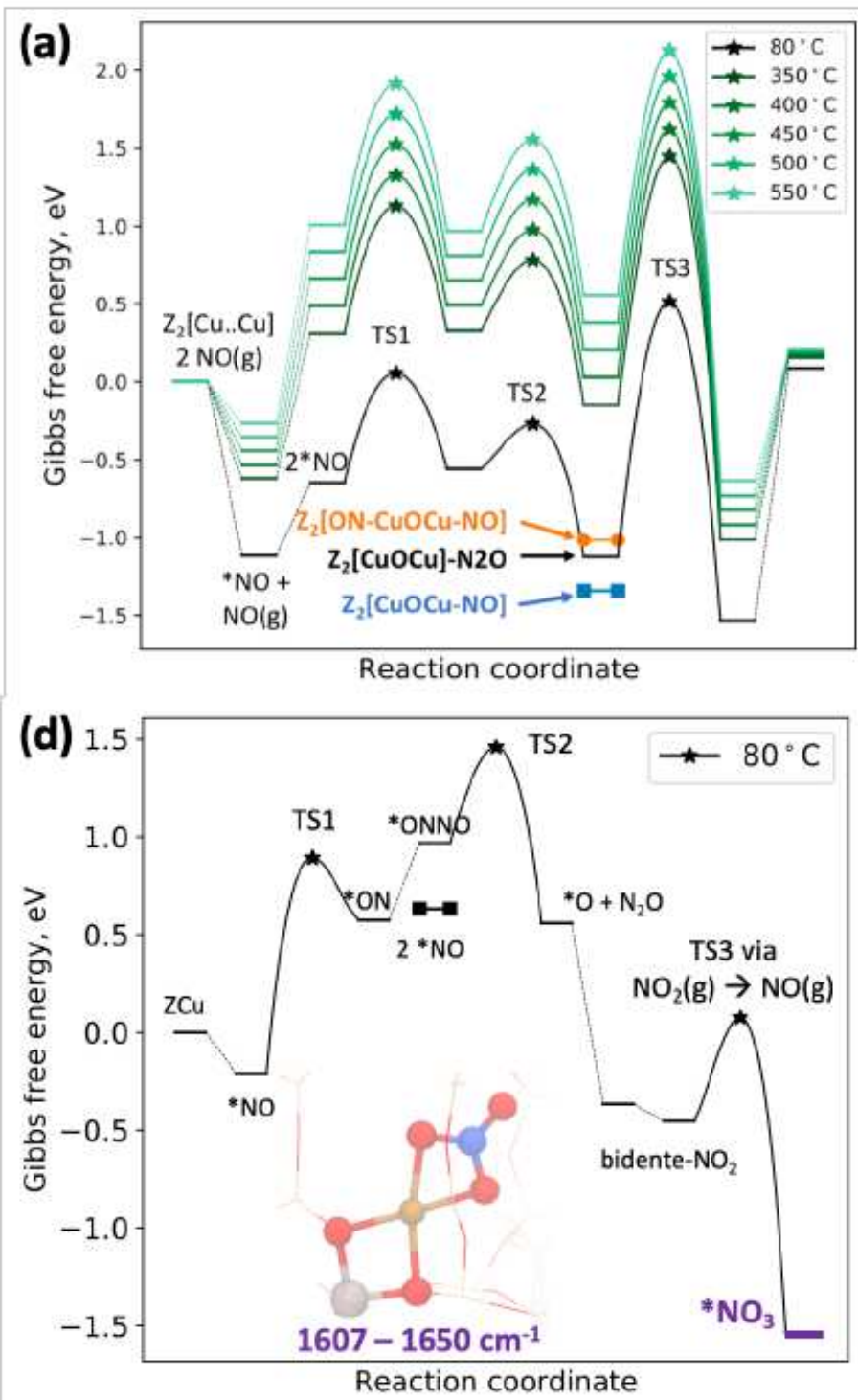

(b)

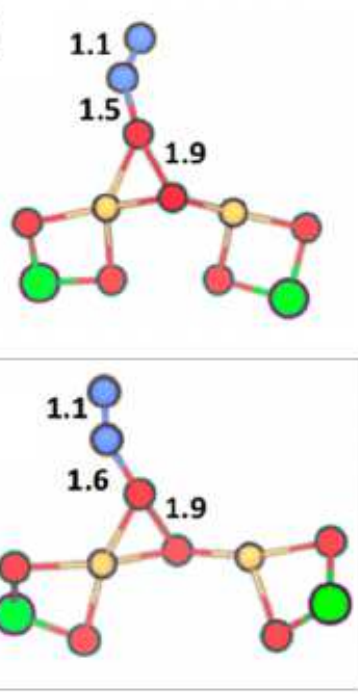

(c)

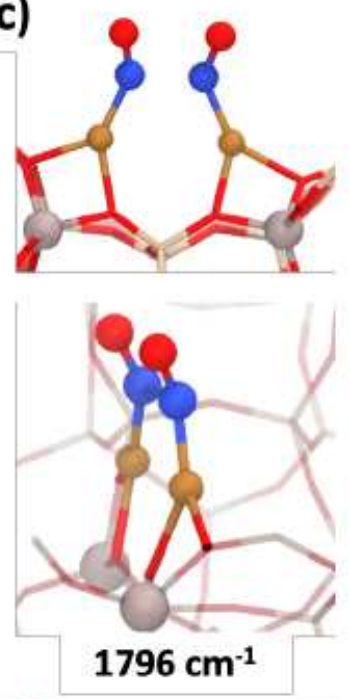

(e)

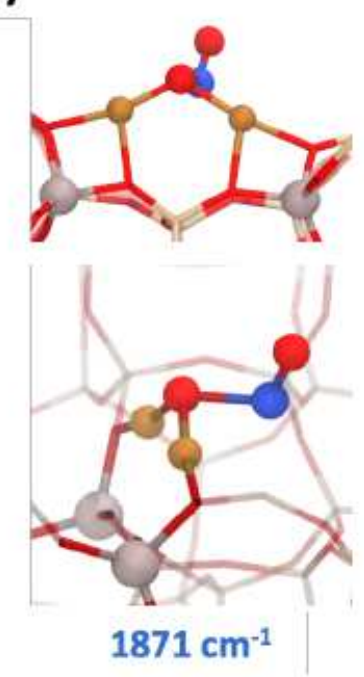

(f)

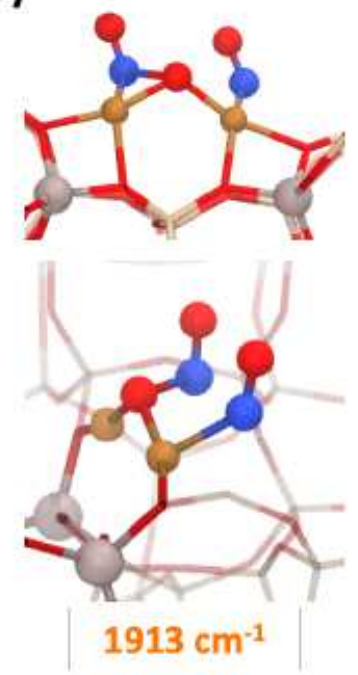

\section{Figure 3}

(a) DFT calculated free energy diagrams at various temperatures for NO decomposition by Cu dimers in 1T-MFl; free energies of one and two NO bound dimers are shown in orange and blue, respectively. (b) The transition states for $\mathrm{N} 2 \mathrm{O}$ decomposition for $1 \mathrm{~T}$ (upper) and 2T (lower) models (Red: O, Blue: N, Yellow: Cu,

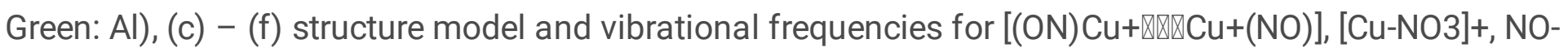
[Cu-O-Cu]2+ and [(NO)Cu-O-Cu(NO)]2+, respectively (Red: O, Blue: N, Yellow: $\mathrm{Cu}$, Gray: Al). The free energy diagram for the isolated-Cu site is shown in (d) at $80^{\circ} \mathrm{C}$. 

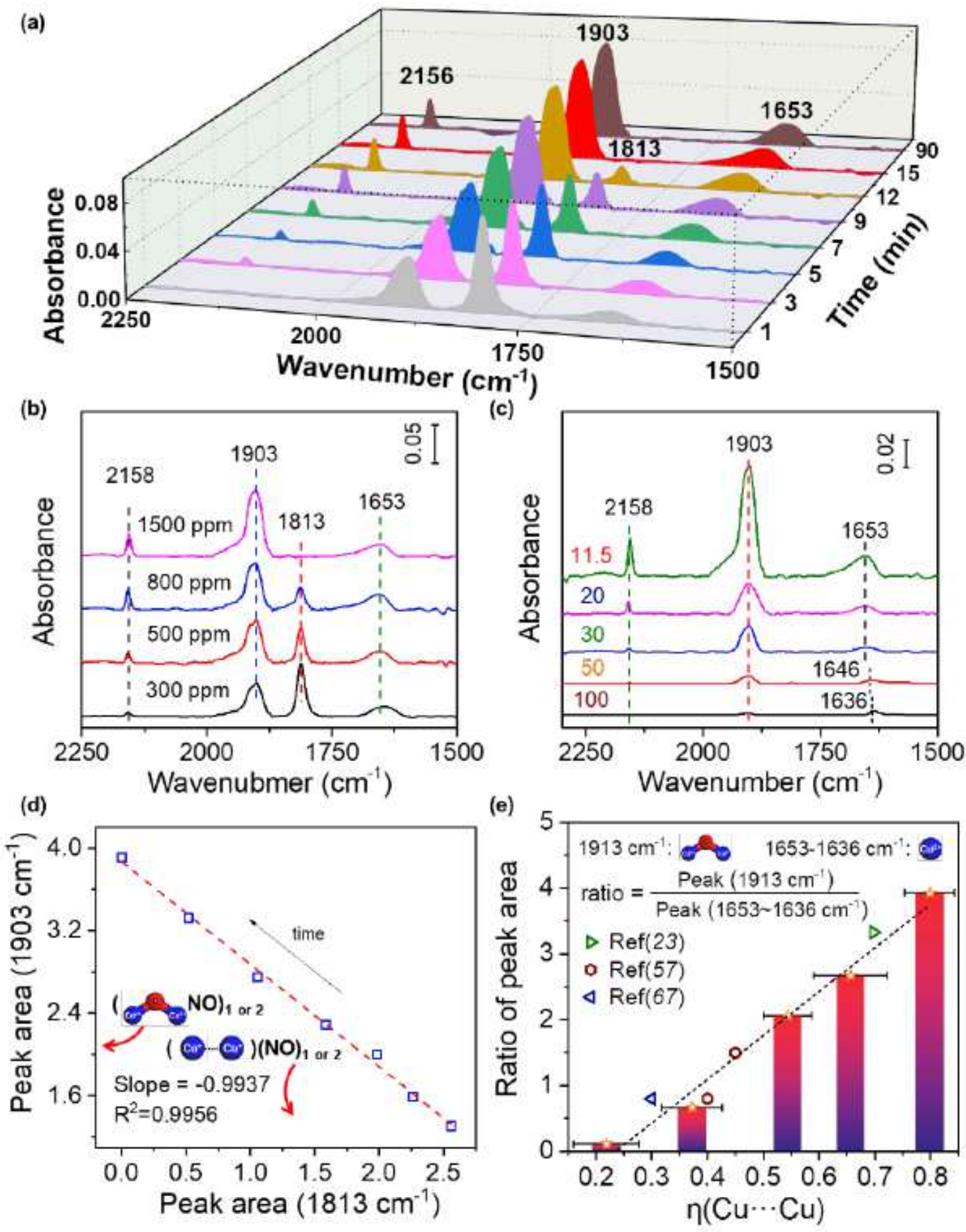

\section{Figure 4}

Characterization and quantification of Cu dimers in Cu-ZSM5 zeolites. (a) Time dependence DRIFTs of NO isothermal adsorption at $80^{\circ} \mathrm{C}$ on Cu-ZSM5-11.5 at 1500 ppm. (b) Pressure dependence DRIFTs of NO isothermal adsorption at $80^{\circ} \mathrm{C}$ on Cu-ZSM5-11.5 at $15 \mathrm{~min}$. (c) DRIFTs of NO isothermal adsorption at $80{ }^{\circ} \mathrm{C}$ on Cu-ZSM5 with different $\mathrm{Si} / \mathrm{Al}$ ratios at $1500 \mathrm{ppm}$ and $15 \mathrm{~min}$. (d) Correlation of integrated peak areas of $1903 \mathrm{~cm}-1$ peak and $1813 \mathrm{~cm}-1$ peak in DRIFT spectra of NO isothermal adsorption at 80 
${ }^{\circ} \mathrm{C}$ and $1500 \mathrm{ppm}$ on Cu-ZSM5-11.5 at different times. (e) Correlation of area ratios of $1903 \mathrm{~cm}-1$ peak and $1813 \mathrm{~cm}-1$ peak in DRIFT spectra of NO isothermal adsorption at $80^{\circ} \mathrm{C}$ on Cu-ZSM5 and Cu dimer fraction from DFT calculation and TPR measurements.

(a)

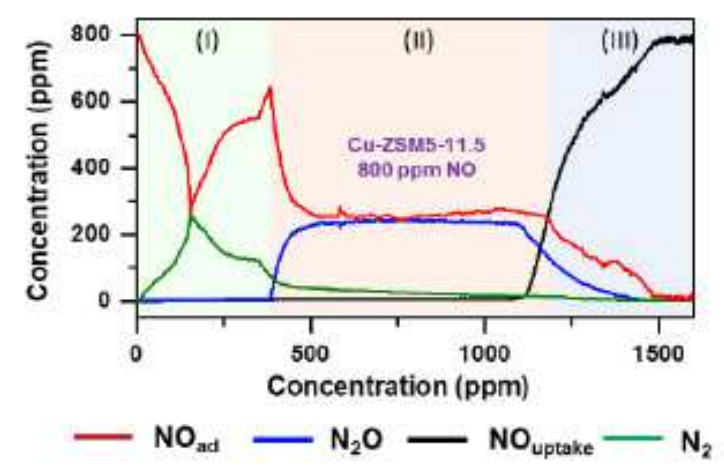

(c)

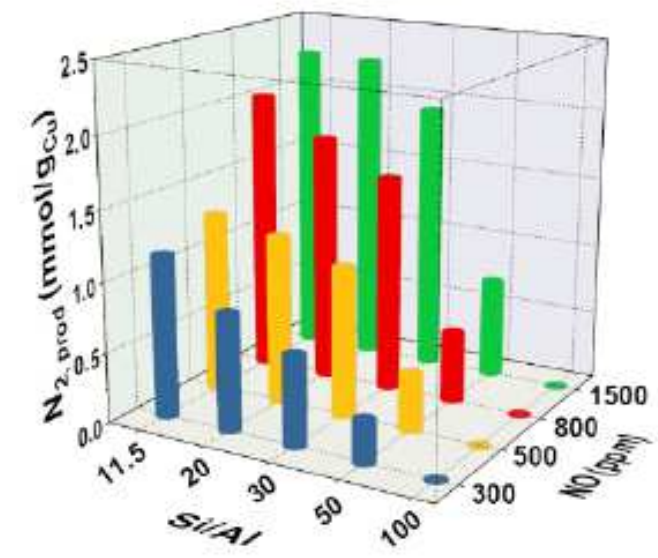

(e)

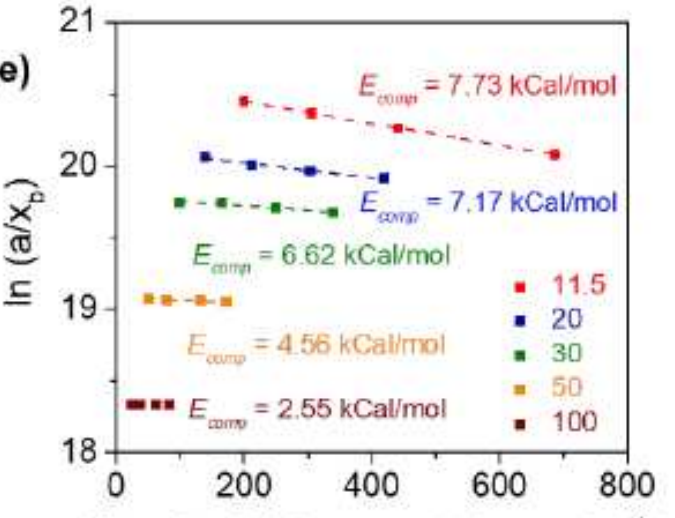

Absorbed $\mathrm{NO}$ amount $\left(\mathrm{a}, \mu \mathrm{mol} \mathrm{g}^{-1}\right)$

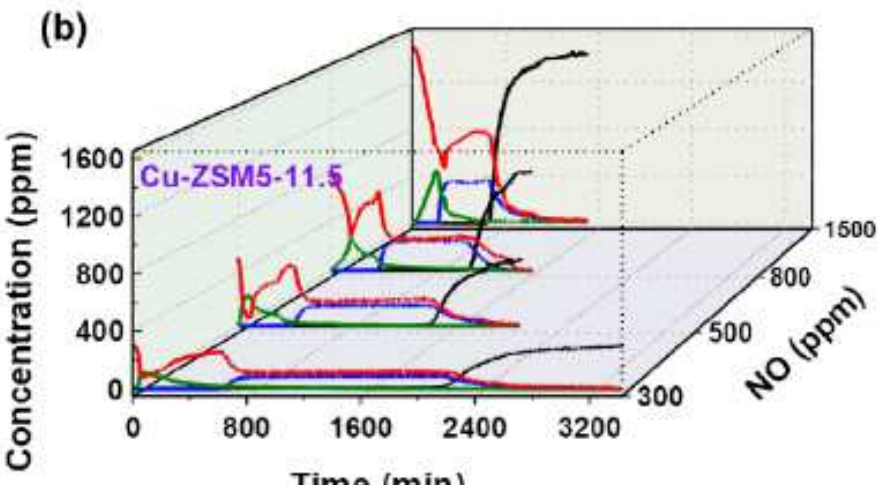

Time (min)

(d)

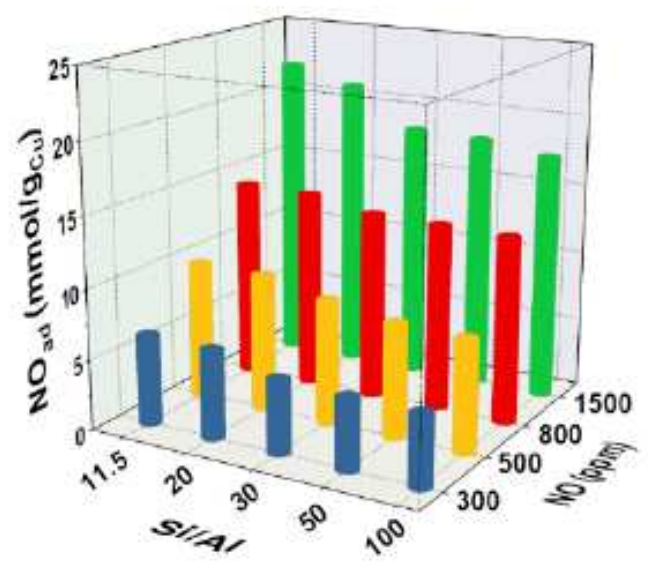

(f)

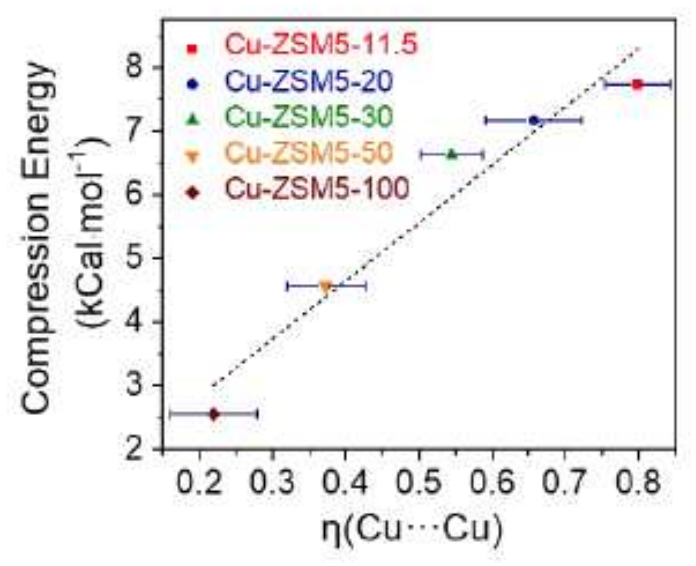

\section{Figure 5}

NO Isothermal adsorption profiles. (NOad: red, N2,prod: green, N2Oprod: blue, NOuptake: black) (a) Time dependent profiles of outlet concentrations of NO, N2O and N2 during $\mathrm{NO}$ isothermal adsorptions at $80^{\circ} \mathrm{C}$ with 800 ppm of NO on Cu-ZSM5-11.5. (b) Time dependent plot of outlet concentrations of NO, N2O and $\mathrm{N} 2$ during NO isothermal adsorptions at $80^{\circ} \mathrm{C}$ with different pressures of NO for Cu-ZSM5-11.5. (c) plot 
of N2 production per Cu site during NO isothermal adsorption at different NO pressures on the five CuZSM5. (d) plots of adsorbed NO per Cu site during NO isothermal adsorption at different NO pressures on Cu-ZSM5 zeolites. (e) Ono-Kondo plots for compression energies of Cu-ZSM5 zeolites. (f) Correlation of calculated compression energy and average Cu-Cu distance in Cu-ZSM5 zeolites.

(a)

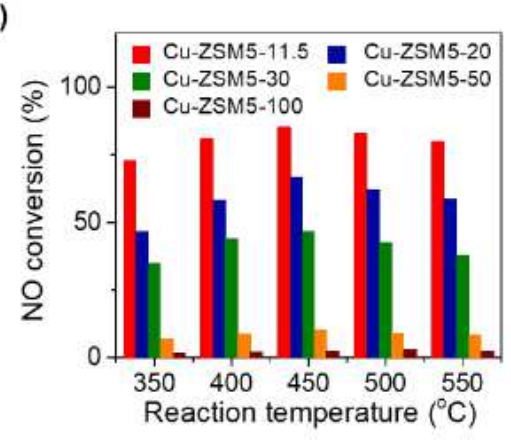

(d)

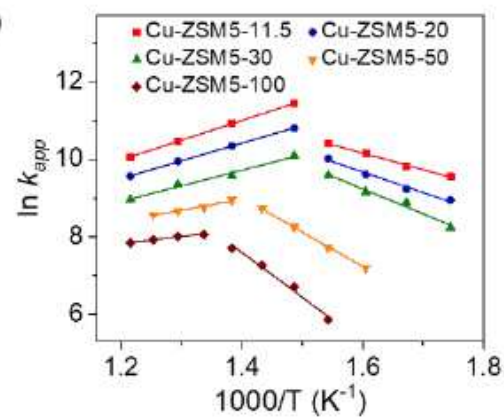

(b)

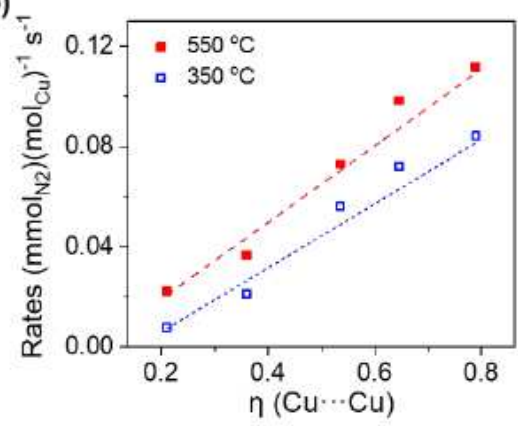

(e)

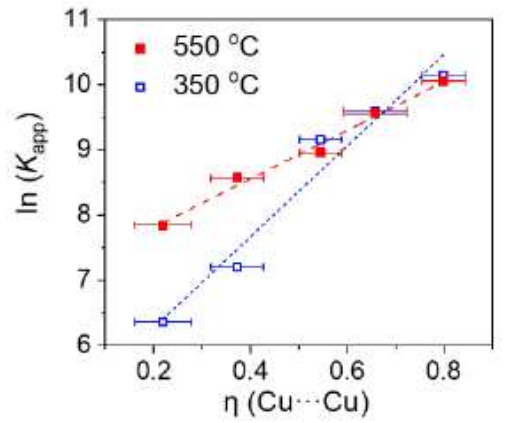

(c)

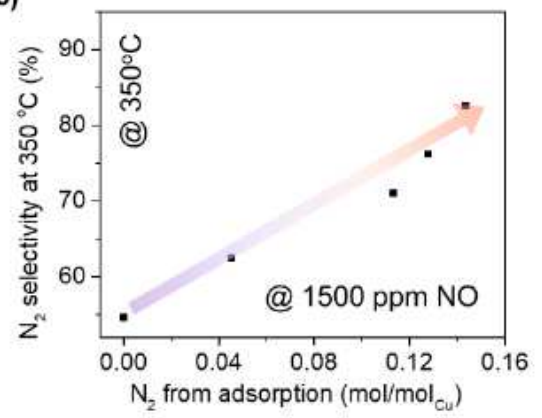

(f)

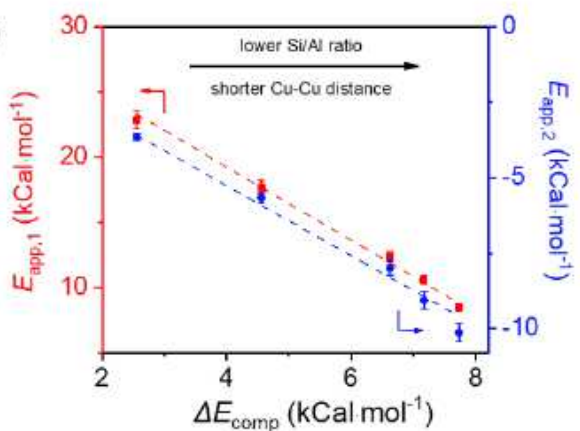

\section{Figure 6}

Catalytic performance and Kinetics of NO Decomposition. (a) Conversions of NO over different Cu-ZSM5. (b) Correlations between rates of $\mathrm{N} 2$ at $350,550^{\circ}$ Cand fractions of Cu dimers. (c) Trends of N2 selectivity at 350 depending on $\mathrm{N} 2$ production during $\mathrm{NO}$ isothermal adsorptions at $80^{\circ} \mathrm{C}$ with $1500 \mathrm{ppm}$ of NO on Cu-ZSM5 zeolites. (d) Arrhenius plots for rate constants vs 1/T. (e) Correlations between In(Kapp) at 350, $550^{\circ} \mathrm{C}$ and fractions of $\mathrm{Cu}$ dimers fractions. (f) Correlation of apparent activation energies at low temperatures (red, left) and at high temperatures (blue, right) with compression energy derived from OnoKondo coordinates. 

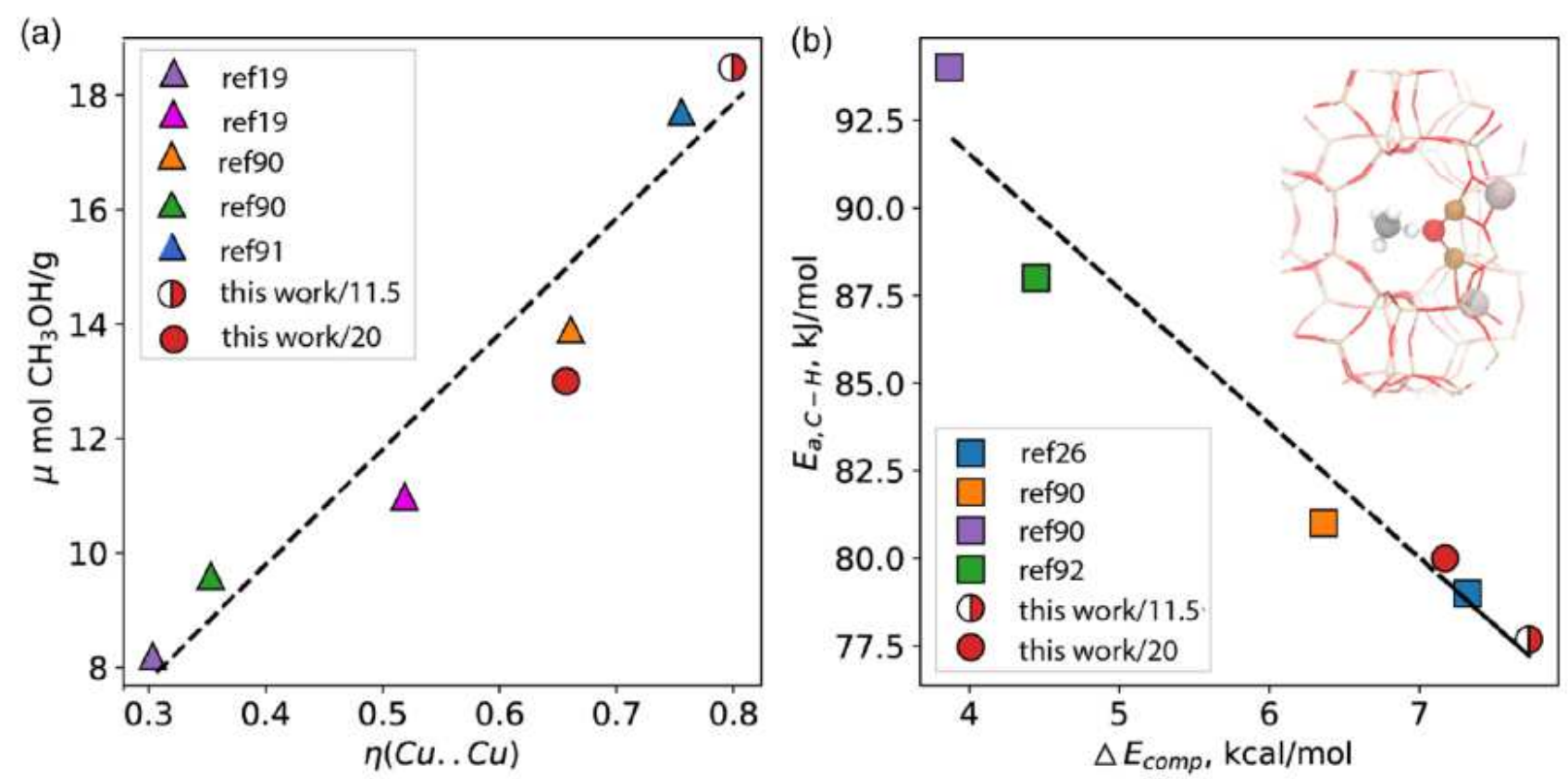

\section{Figure 7}

Catalytic study of methane to methanol by using Cu-ZSM5 from the literature and this work. (a) Correlations between the methanol yields with Cu dimers fractions; (b) Correlation of apparent methane activation energies with compression energies. Hereby the $\mathrm{Cu}$ dimers fractions and compression energies are derived by fitting the $\mathrm{Cu}$ densities from literature into the scaling established in Figure $2 \mathrm{~d}$ and Figure $5 f$.

\section{Supplementary Files}

This is a list of supplementary files associated with this preprint. Click to download.

- 2020820CuZSM5DeNOxSI.pdf 